\title{
Intelecto agente, motor inmóvil y Dios en Aristóteles*
}

\author{
René Farieta \\ Universitaria Agustiniana
}

\begin{abstract}
Resumen: El presente artículo se enfrenta al problema clásico sobre cómo interpretar lo que Aristóteles, en de An. III, 5, denomina "el intelecto que produce todas las cosas", llamado comúnmente intelecto agente. Históricamente, se han presentado dos lecturas: una, que se remonta a Alejandro de Afrodisia, que lo asocia con el motor inmóvily con la divinidad y otra, asociada a Teofrasto pero que tiene en Filópono y St. Tomás de Aquino a sus principales representantes, que lo considera una facultad puramente humana. Esta última interpretación ha sido históricamente la más sostenida; sin embargo, en tiempos recientes ha habido un resurgimiento de interpretaciones del intelecto agente como "divino" (Caston, Frede, Burnyeat, entre otros). Lo que queremos mostrar en este texto es que este resurgimiento se debe, más que a una reinterpretación del intelecto agente, a una comprensión diferente de la divinidad en la filosofia aristotélica, con caracteristicas inmanentes y más próximas al intelecto humano.
\end{abstract}

Palabras clave: Aristóteles; intelecto agente; motor inmóvil; Dios; psicología aristotélica; teología aristotélica

\begin{abstract}
Agent Intellect, Unmoved Mover and God in Aristotle". This article faces the classic problem of the interpretation of what Aristotle calls in de An. III, 5 "the intellect that produces all things", which is commonly named agent intellect. Historically, there have been two approaches: one that goes back to Alexander of Aphrodisias, who associates the agent intellect with the unmoved mover and the divinity, and another one, associated with Theophrastus but whose major representatives are Philoponus and St. Thomas of Aquinas, who consider that agent intellect is an exclusively human faculty. This last interpretation has been the most accepted historically. Nevertheless, in recent years there has been a resurgence of interpretations of the agent intellect as divine (Caston, Frede, Burnyeat, and others). What we want to demonstrate in this article is that this revival, more than responding to a reinterpretation of the agent intellect, is due to a different understanding of the divinity in Aristotle's philosophy, which supposes immanent characteristics closer to the human intellect.
\end{abstract}

Keywords: Aristotle; agent intellect; unmoved mover; God; Aristotelian Psychology; Aristotelian Theology

* Este artículo fue realizado en el marco del proyecto de investigación INV-2016I-005- Motor inmóvil, intelecto agente y Dios en la obra de Aristóteles, financiado por la Universitaria Agustiniana. 


\section{Introducción}

Uno de los planteamientos más célebres en la obra de Aristóteles, tan recordado como polémico, es la división del intelecto en dos: uno que llega a ser todas las cosas y otro que produce todas las cosas; como aparece en $D e$ Anima, III, 5. La polémica sobre cómo entender esta división y en qué consiste cada uno de los intelectos es muy antigua. Se le atribuye ya a Alejandro de Afrodisia, en su comentario al De Anima escrito en el siglo III d.C., una primera interpretación que asimila el intelecto que produce todas las cosas con la causa primera -es decir, al motor inmóvil- (de An. 89, 9-19) ${ }^{1}$ y, como consecuencia de esto, con Dios (de An. 109, 23-110). A esta propuesta interpretativa se opuso Juan Filópono, quien refuta, punto por punto, la interpretación alejandrina (in de An. 534-542), defendiendo que el intelecto agente es netamente humano y completamente distinto del motor inmóvil. En esto fue secundado por Temistio (in de An. 110.18-28), por Sofonias y también por Santo Tomás (In de An. III, lect. 10; Suma Teológica, 1a, q79, a4-5) cuya influyente interpretación, según la cual el intelecto agente es el intelecto humano, ha sido la más aceptada a lo largo de la historia. Según Shields, esta interpretación provenía de Teofrasto ${ }^{2}$. Una interpretación cercana a la de Alejandro fue adoptada por los filósofos árabes -especialmente por Avicena y Averroes- para quienes el intelecto agente era una sustancia trascendente, pero no exactamente Dios, sino el eslabón final en una cadena de inteligencias divinas, cadena que conecta a Dios con el ser humano ${ }^{3}$. La versión árabe del intelecto agente está fuertemente conectada no solo con la interpretación de Alejandro de Afrodisia, sino, al parecer, también con la de neoplatónicos como Marino o Albino (Juan Filópono, in de An. 535.5-8), e incluso con el mismo Plotino, para quien la Inteligencia -que correspondería al intelecto agente- es emanada a partir de lo Uno, que es la primera causa del universo (Eneadas, V.1; VI.9) ${ }^{4}$.

\footnotetext{
1 Las abreviaturas de las obras de fuentes clásicas y medievales las hemos tomado de Rodríguez Somolinos, J., Diccionario Griego-Español. Disponible en: http://dge.cchs.csic.es/lst/lst1.htm.

2 Cf. Shields, Ch., Aristotle. De Anima. Trad. \& Notes, Oxford: Clarendon Press, 2016, pp. 315-316.

3 Como prueba Davidson, H.A., Alfarabi, Avicenna, and Averroes on Intellect, Nueva York: Oxford University Press, 1992, pp. 13-18.

4 De acuerdo con Taylor, R.C., "The Agent Intellect as 'Form for Us' and Averroes's Critique of al-F'r'bî”, en: Proceedings of the Society for Medieval Logic and Metaphysics, v. V (2005), pp. 18-32,
} 
En los últimos tiempos ha habido un resurgimiento de este tipo de interpretaciones similares o cercanas a la de Alejandro de Afrodisia ${ }^{5}$. Estas interpretaciones del intelecto agente como Intelecto Divino ${ }^{6}$ se han opuesto sistemáticamente a su lectura como Intelecto Humano (como la lectura que propone Santo Tomás). En el presente artículo, haremos una evaluación tanto de los argumentos a favor como en contra de estas lecturas cercanas a la alejandrina en los últimos tiempos, tratando de explicar el resurgimiento de esta interpretación y de dar luces con respecto a la solución del problema. Revisaremos los principales argumentos en contra de esta lectura ${ }^{7}$ y mostraremos cómo estas interpretaciones recientes podrian hacerle frente. Finalmente, concluiremos que, pese a las críticas que puede recibir esta interpretación, hay elementos en la obra aristotélica que parecen hacer viable o admisible una interpretación próxima a la alejandrina. Por ello, mostraremos que en los últimos años ha cambiado el significado de conceptos importantes que han estado a la base del problema en toda la tradición filosófica y teológica, en especial el concepto aristotélico de "lo divino" -y, por lo tanto, de Dios-, pero también conceptos como el de "separabilidad", que resulta clave en ambas interpretaciones. Para esto, en una primera sección, revisaremos las críticas a la interpretación alejandrina y, en una segunda, revisaremos cómo las posiciones contemporáneas responden o podrían responder a estas críticas a partir de diferentes textos aristotélicos. Así, una comprensión de lo divino diferente a la del cristianismo medieval permitirá

Averroes elabora su interpretación del intelecto agente oponiéndose principalmente a la interpretación de Alfarabi y acercándose más a la de Plotino.

5 Frede, M., "La théorie aristotélicienne de 1' intellect agent", en: Romeyer-Dherbey, G. y C. Viano (eds.), Corps et âme. Sur le De anima d'Aristote, París: Vrin, 1996, pp. 377-390; Caston, V., "Aristotle's Two Intellects: A Modest Proposal", en: Phronesis, v. XLIV, 3 (1999), pp. 199-227; Burnyeat, M.F., Aristotle's Divine Intellect, Winsconsin: Marquette Universty Press, 2008. De acuerdo con Berti, E., "Aristotle's Nous Poietikos: Another Modest Proposal”, en: 2nd International Colloquium on Aristotle, Interdisciplinary Centre for Aristotle Studies, 2014 (disponible en http://www. dikam.auth.gr/sites/default/files/attachements/Paper.pdf), esta se ha convertido en la interpretación mainstream en los últimos tiempos, aunque históricamente es la menos aceptada. Caston (Caston, V., "Aristotle's Two Intellects: A Modest Proposal”, p. 201, n. 3) y Shields (Shields, Ch., Aristotle. De Anima. Trad. \& Notes, pp. 314-315) presentan una buena compilación de otras interpretaciones cercanas a las de Alejandro de Afrodisia posteriores a Tomás de Aquino.

6 Como las llama Shields, Ch., Aristotle. De Anima. Trad. \& Notes, pp. 312-329.

7 Tal como los propone Boeri, M.D., "Alejandro de Afrodisia como intérprete de la noética aristotélica”, en: Estudios de Filosofia, v. XL (2009), pp. 79-107, quien presenta la discusión de manera sistemática y presenta su propia versión de por qué es inaceptable la lectura alejandrina -o cualquier otra lectura similar-. Esta crítica se encuentra articulada de manera más general con su traducción al español del De Anima en Boeri, M.D. (trad.), Aristóteles. Acerca del Alma-De Anima. Introducción, Traducción y Notas, Buenos Aires: Colihue, 2010. 
una mejor comprensión tanto de conceptos de intelecto agente como del motor inmóvil en la obra aristotélica.

Para esto, en una primera parte de este trabajo, presentaremos las principales objeciones a la idea de concebir al intelecto agente como divino, sobre todo, porque la idea de una sustancia separada que a la vez es parte y compone otra sustancia -en este caso, el ser humano y, en particular, el intelecto humano- es contraria a toda la ontología aristotélica. En un segundo momento, propondremos una interpretación según la cual la separabilidad de la cual habla Aristóteles con respecto al intelecto es una separabilidad conceptual, pero no ontológica. No se trata de una sustancia en sentido pleno de la palabra -a saber, como una entidad particular-, sino que dicha separabilidad es más bien conceptual. Esto quiere decir que, así como se puede hablar de forma separada de la materia -separación que se da en la abstracción, pero no en la sustancia misma-, así también el intelecto agente se separa conceptualmente del intelecto pasivo. De este modo, así como hay casos en los que a la forma se le denomina, también, sustancia, del mismo modo, al intelecto agente se le concibe como separado y como sustancia, pero no por ser sustancia sino por ser lo que determina la sustancia. De aquí, pasaremos a la parte final de este texto, en donde veremos que es justamente este papel determinativo del intelecto agente el que nos conducirá a mostrar que es posible identificarlo con el motor inmóvil. En este sentido, la presentación que haremos de él no será en tanto sustancia, sino en tanto lo que determina la sustancia. Así, concluiremos que es en la reinterpretación de ambos conceptos que podemos mostrar su identificación. Esto es, como mostraremos, lo que ha revivido esta interpretación alejandrina, o una versión modificada de la misma.

\section{El problema: la posibilidad de un intelecto "separado"}

Dice Aristóteles en el capítulo 5 del libro III de De Anima: "Y también hay un intelecto tal porque llega a ser todas las cosas [o pasivo], y otro porque crea todas las cosas [o activo]... Y también así el intelecto [activo] es separado, impasible y sin mezcla, siendo actividad en tanto sustancia; en efecto, siempre es más valioso lo que actúa que lo que padece, y el principio [es más valioso] que la materia...; solamente este es inmortal y eterno...; y sin este nada intelige" (de An. 430a14-19, énfasis añadido) ${ }^{8}$.

\footnotetext{
8 A menos que se indique lo contrario, todas las traducciones son nuestras. Para el texto griego hemos seguido la edición de Ross, W.D., Aristotle. De Anima, Edited with Introduction and
} 
Estas pocas líneas han sido el centro de un sinnúmero de interpretaciones con respecto a cómo concibe Aristóteles el intelecto agente y qué características tiene. Parece ser, pues, bastante enfático en que se trata de algún tipo de sustancia separada y, además, en que es la única que es inmortal y eterna, por lo tanto no se trataría del intelecto humano, sino de algo completamente diferente. Sin embargo, resulta muy controversial concebir al intelecto agente de esta manera, a saber, como si fuese una sustancia separada. Pues de ser así, el intelecto agente sería un tipo particular de sustancia inmaterial que tendría existencia en sí misma, independiente de todas las demás sustancias, lo cual la haría, incluso, independiente del intelecto humano. Por esta razón, iniciaremos el presente artículo señalando los problemas de suponer el intelecto agente como Dios, siendo este separado de las demás sustancias -incluso del intelecto humano-, del cual, puesto en estos términos, o no haría parte o se estarian violando los principios aristotélicos de aquello en lo que consiste ser una sustancia9.

De entrada, con respecto a este "intelecto separado", tenemos dos posibilidades: que tal intelecto haga parte, y componga al ser humano en general, o que no lo componga, y sea una sustancia particular e independiente del ser humano (y de todas las demás sustancias). Examinemos por aparte cada una de estas posibilidades, junto con sus respectivos problemas.

Supongamos, en primer lugar, que este "intelecto agente" hace parte constitutiva de una sustancia particular: el ser humano individual, el cual, como afirma Aristóteles en Categorías (2a10-20), es una sustancia en sentido propio. Pero el intelecto agente es separado y sin mezcla, por lo que esta primera posición resulta contradictoria con la teoría aristotélica de la sustancia. En efecto, en tal caso el ser humano tendría una característica bien particular: sería una sustancia que contendría otra sustancia, y esto, en la ontología aristotélica, es absurdo. Miremos este problema con más detalle.

La principal serie de argumentos en contra de la idea de una sustancia compuesta de sustancias aparece en Metaph. VII 13-16, en donde Aristóteles

\footnotetext{
Commentary, Oxford: Oxford University Press, 1961.

9 Algunos de los autores que se oponen a esta posición del intelecto agente como separado del intelecto humano son: Rodier, G. (trad.), Traité de l'âme d'Aristote traduit et annoté, París: Leroux, 1900; Ross, W.D., Aristotle. De Anima, Edited with Introduction and Commentary; Robinson H.M., "Aristotelian Dualism", en: Oxford Studies in Ancient Philosophy, v. I (1983), pp. 123-144; Sisko, J., "Aristotle's Nous and the Modern Mind", en: Proceedings of the Boston Area Colloquium in Ancient Philosophy, v. XVI (2000), pp. 177-198; Gerson, L., "The Unity of Intellect in Aristotle's De Anima", en: Phronesis, v. XVIX, 4 (2004), pp. 348-373.
} 
intenta probar que "es evidente que... ninguna sustancia se compone de

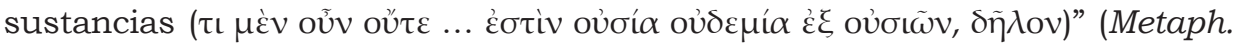
1041a3-5) ${ }^{10}$. De todos los argumentos indicados en estos cuatro capítulos, el que mejor da cuenta del punto que queremos señalar es, quizás, el siguiente: "Es imposible que la sustancia sea compuesta de otras sustancias que se encuentren en completa actualidad; en efecto, lo que es dos cosas en estado de completa actualidad no puede ser una [sola] en estado de completa actualidad, sino que más bien siendo en potencia dos cosas sería una unidad... por lo tanto, si la sustancia es una, no estará compuesta de otras sustancias de este modo [completamente actualizadas]" (Metaph. 1039a3-8) ${ }^{11}$.

Esta es, en términos aristotélicos, la objeción más fuerte que se le puede hacer a cualquier teoría que suponga el dualismo ontológico, es decir, a cualquier ontología que suponga que una misma cosa es, al mismo tiempo, dos sustancias diferentes. Aristóteles señala que esto solo es posible en la medida en que una de las dos sustancias lo sea en potencia, y la otra en estado de actualidad completa ( $\dot{\varepsilon} \vee \tau \varepsilon \lambda \varepsilon \chi \varepsilon i ́ \alpha)$. Parece entonces imposible que el intelecto agente, dadas estas características, sea parte constitutiva del intelecto humano, por lo que el intelecto agente sería una sustancia diferente al ser humano.

De aquí surge la segunda posible interpretación del intelecto agente o, en otros términos, la interpretación alejandrina, según la cual el intelecto agente es el motor inmóvil. Lo que hace pensar que es posible esta asociación entre ambos es el hecho de que cada vez que es mencionado el "intelecto separado", Aristóteles afirma que se encuentra en estado de actualidad completa. Dice así el Estagirita: "Por lo tanto, es preciso que haya un principio tal que sea sustancia en acto. Además, es preciso también que tales sustancias sean carentes de materia; en efecto, es preciso que sean eternas, si es que también alguna otra cosa [aparte de la materia] es eterna. Estas sustancias son, entonces, en acto

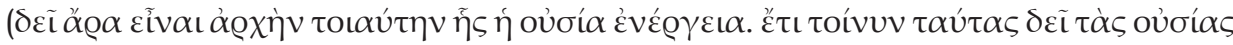

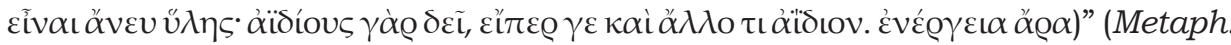
1071b19-22). Así pues, dado que el motor inmóvil se encuentra siempre en acto, es decir, se encuentra siempre en estado de actualidad completa, este motor inmóvil no es parte constitutiva del intelecto humano, con lo que se evita así

\footnotetext{
${ }^{10}$ Hay más o menos acuerdo en que los capítulos 13 a 16 forman una unidad temática. Según Bostock, D., Aristotle Metaphysics Books $Z \& H$, Oxford: Oxford University Press, 1994, p. 232, esta breve frase es la conclusión general de estos capítulos.

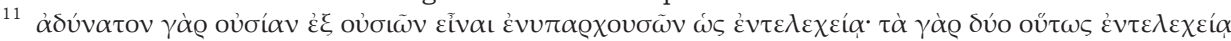

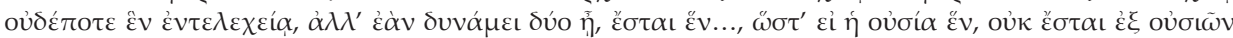

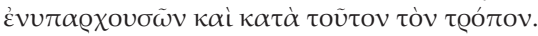


el problema del dualismo ontológico señalado anteriormente, y tendriamos así dos intelectos como sustancias propiamente dichas, pero independientes ontológicamente la una de la otra. Por esto señalaría lo siguiente Aristóteles con respecto al "intelecto activo" de De Anima: "y este intelecto es separado,

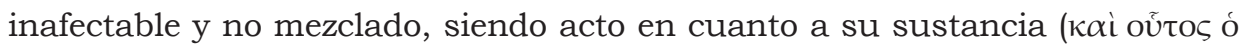

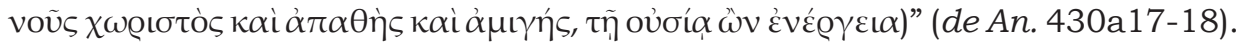
Así, este "intelecto activo" resulta ser siempre en acto, así que no se trataría del intelecto humano, sino de un tipo de sustancia independiente y separada del ser humano en tanto sustancia.

Pero esta segunda posición, al aceptar al intelecto activo como separado y ontológicamente independiente del ser humano, resulta aún más problemática que la primera opción. Si así fuera, ¿qué aporta este a la psicología humana que se está estudiando en De Anima? Tal intelecto separado no aporta ni haría parte del estudio de los seres vivos, ni de la naturaleza cambiante, que es el objeto de estudio de esta obra, tal como menciona Aristóteles justo en su inicio (de An. 402a6-7). El filósofo parece darle unas características similares al intelecto que constituye la vida "más feliz" en los capítulos finales de la Ética Nicomaquea. Si se trata del mismo intelecto, tendriamos, además, serias implicaciones en la comprensión de la propuesta ética aristotélica, pues de esta posición se seguiria, entonces, que la felicidad del intelecto a la cual se refiere Aristóteles en Ética Nicomaquea X, 7-8, no es la felicidad humana, sino otro tipo de felicidad, puramente divina ${ }^{12}$. No obstante, si este fuese el caso, esta felicidad resulta "impracticable" es decir, imposible de llevar a cabo, o de alcanzar por un ser humano. Esto tendría como consecuencia que su propuesta más acabada con respecto a la felicidad fuera completamente inviable y cayera en las mismas críticas que había hecho a la propuesta de Platón. Así pues, con respecto a una versión similar del "intelecto activo" que tenga características similares a las del "motor inmóvil", o a cualquier tipo de sustancia puramente inteligible, tenemos un grave dilema: si es una sustancia particular, independiente de las demás, la propuesta de Aristóteles no tiene nada que ver con el ser humano o la naturaleza, pues resulta en el campo de lo físico completamente irrealizable, pero si es una parte que compone al ser humano -o a cualquier otra sustancia-, entonces está contradiciendo la ontología aristotélica.

${ }^{12}$ Como defiende Bush, S., "Divine and Human Happiness in Nicomachean Ethics", en: Philosophical Review, v. CXVII, 1 (2008), pp. 49-75. 
Ambas posiciones resultan bastante problemáticas para la comprensión de la filosofia aristotélica en general. Para resolver este problema, queremos entonces, en el presente escrito, proponer una interpretación distinta de esta "sustancia inmaterial", que pudiera salvar estos problemas que hemos señalado. Así, el recorrido argumentativo que haremos partirá de presentar lo que llamaremos en la siguiente sección una interpretación conceptual, pero no ontológica, de la sustancia inmaterial, para evitar, así, los problemas de suponer que el intelecto activo es una sustancia independiente y, con ello, también al dualismo ontológico. Como mostraremos en la sección 3, cuando Aristóteles habla del intelecto activo no se está refiriendo a una sustancia particular que se distingue de las demás sustancias, sino que se está refiriendo al concepto mismo de sustancia, y en particular, al concepto de forma; para utilizar la expresión que Aristóteles utiliza en De Anima, "el intelecto es la forma de las formas (ó voũs عĩoos cỉoũv)" (de An. 432a2). Así, el intelecto, y en particular el intelecto agente, es aquello que hace posible cualquier otra forma y cualquier otro concepto. Se trata, entonces, de un concepto de segundo orden, en tanto es un concepto que se refiere no directamente a objetos, sino a otros conceptos. En dicha sección explicaremos con detalle la noción de "concepto de segundo orden". Posteriormente, en la sección 4, mostraremos cómo esta misma interpretación conceptual permitiría conectar el intelecto agente con el motor inmóvil. Esto se debe a que el motor inmóvil cumple la misma función al ser el "intelecto que se intelige a sí mismo". Para terminar, mostraremos cómo esta interpretación solucionaría algunos de los problemas más complejos tanto en el campo de la psicología aristotélica como en el de la ontología, y, por qué no, también en el de la ética.

\section{El intelecto agente}

Hemos presentado una hipótesis que va a conducir nuestro camino hacia una interpretación del "intelecto separado" como equivalente al "motor inmóvil": se trata de la hipótesis de la prioridad conceptual del intelecto agente sobre las demás formas. Queremos mostrar en qué sentido es posible aceptar que estas dos expresiones - “intelecto agente" y "motor inmóvil”- se refieren exactamente a lo mismo; pero, más aun, queremos aclarar qué entiende Aristóteles por cada una de ellas, y, finalmente, en qué sentido habla Aristóteles de un "intelecto separado", pues lo que queremos proponer es que este intelecto separado lo es en tanto concepto, más precisamente, en tanto la fuente y origen de los 
conceptos; o mejor dicho, en tanto condición de posibilidad de todos los demás conceptos, es decir, de las formas. Es en este sentido que vamos a entender la expresión según la cual el intelecto es "forma de formas".

\section{a. El intelecto y las potencias del alma}

Demos un repaso rápido de los problemas que Aristóteles mismo presenta con respecto del intelecto. Cuando, en el inicio del De Anima, Aristóteles clasifica los tipos de capacidades que tienen los seres vivos y el tipo de actividades que lleva a cabo cada ser vivo, expone una duda con respecto del intelecto, pues parece ser la única capacidad que es posible "activar" sin requerir del cuerpo (de An. 403a8-13). Esta es, precisamente, la duda que puede conducir a pensar en una especie de dualismo ontológico en el ser humano. Lo que haremos a continuación es dar una interpretación no dualista de los pasajes de De Anima que aparentemente comprometen a Aristóteles con un dualismo ontológico ${ }^{13}$.

Tal como ha sido defendido por Boeri -tesis a la cual nos suscribimos parcialmente-, "la distinción 'intelecto paciente-intelecto agente' no es más que la aplicación del esquema hilemórfico a la actividad de pensar"14. Al definir el alma, Aristóteles hace una aclaración importante con respecto a los seres vivos y el alma: el ser vivo es compuesto de materia forma y, en este sentido, es sustancia en tanto compuesto. Por ello, dice: "Todo cuerpo natural que parti-

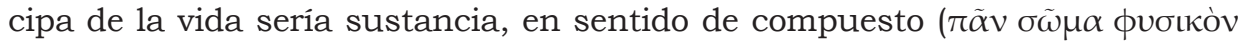

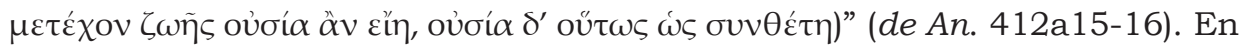
este caso, se trata de compuesto de materia y de forma. Sin embargo, el alma es sustancia en tanto forma; así aclara Aristóteles más adelante: "Es necesario entonces que el alma sea sustancia en sentido de forma de un cuerpo natural

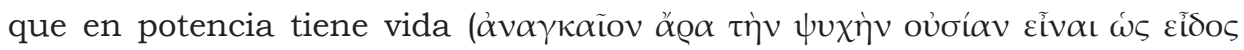

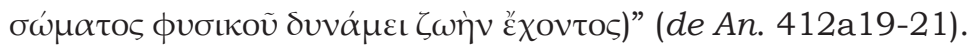

\footnotetext{
${ }^{13}$ Una interpretación similar, no ontológica sino conceptual, de la separación del intelecto es propuesta recientemente en Miller, F.D.Jr., "Aristotle on the Separability of Mind", en: Shields, Ch. (ed.), Oxford Handbook of Aristotle, Oxford: Oxford University Press, 2012, pp. 306-339, a la cual también nos suscribimos, aunque con algunas variaciones que presentamos a continuación. ${ }^{14}$ Boeri, M.D., "Alejandro de Afrodisia como intérprete de la noética aristotélica", p. 81. Nos suscribimos parcialmente a esta tesis porque al alma no se le puede aplicar, en sentido estricto, la distinción forma-materia, pues el alma es ya forma. El "esquema hilemórfico", en el caso específico del alma, hay que entenderlo más en términos de la relación potencia-acto que en la relación materia-forma-compuesto, el cual es el sentido puramente físico del término. Lo que Boeri denomina el "esquema hilemórfico" es entonces una clasificación de diferentes tipos de potencialidades y actualizaciones, de entre las cuales la distinción intelecto agente-intelecto pasivo es el nivel más alto al que puede llegar la aplicación de dicho esquema.
} 
De esta manera, Aristóteles define el alma en relación con la distinción forma-materia, pero luego, con más detalle, introduce a su vez la distinción potencia-acto con unas características muy específicas del tipo de "acto" que es el alma. Así, Aristóteles distingue dos sentidos en los que se da el acto, uno de los cuales es el del alma: "en un sentido [el acto es] como el conocimiento, en otro como el teorizar. Es evidente que [el alma] es como el conocimiento ( $\eta$ $\mu \dot{\varepsilon} v$

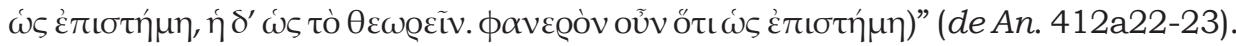
Esta distinción, fundamental para definir al alma, lleva a Aristóteles a concluir

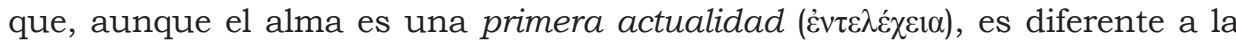
segunda actualidad, que es la actividad misma, como lo es el teorizar (es decir, hacer uso del conocimiento, conocer en acto). Si bien el alma es una actualidad de un cuerpo, con respecto a la segunda actualidad esta funciona, más bien, como una potencia. Unos capítulos más adelante, Aristóteles aclara, entonces, que "es preciso también distinguir sobre la potencia y la actualidad... Así, por una parte, podriamos decir que alguien es un conocedor como si dijéramos que 'el hombre es conocedor' porque el hombre está entre las cosas que conocen; i.e., que tienen conocimiento. Pero, por otra parte, también decimos que ya es conocedor el que tiene la gramática. Cada uno de ellos es en potencia, pero de maneras distintas. El primero, porque su género y su materia es de tal clase El segundo, porque puede teorizar cuando quiera, si nada externo se lo impide. El que ya está teorizando es conocedor en actualidad y en sentido propio de que 'esto es A'. Los dos primeros, aunque son conocedores en potencia, llegan a ser conocedores en acto, pero el primero por ser alterado a través del aprendizaje y usualmente por transformarse desde la disposición opuesta, mientras que el otro, por tener la aritmética o la gramática, pero no estarla ejercitando, [está en potencia] de otra manera" (de An. 417a22-b2) ${ }^{15}$.

De aquí que, aunque el alma sea una actualidad, es una primera actualidad que, con respecto a la segunda actualidad, podría considerarse, más bien, como una potencia. Sin embargo, no es una potencia en sentido estricto, dependiente de la materia (como en el primer caso mencionado en la cita: como

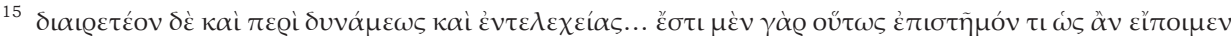

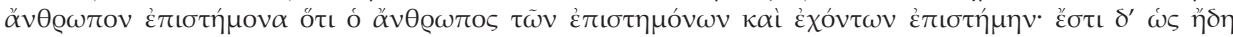

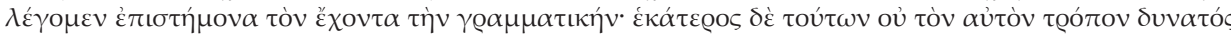

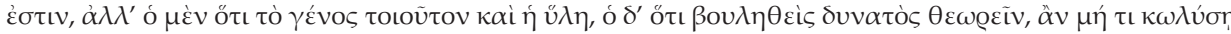

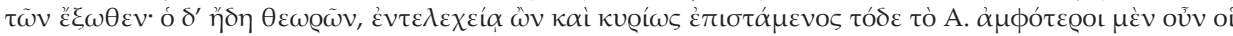

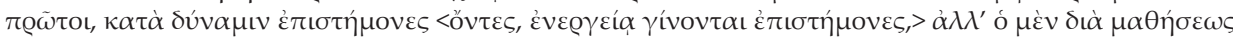

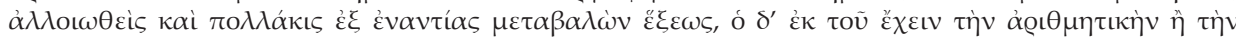

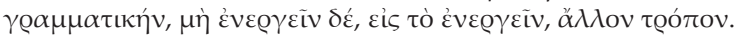


el que tiene la "materia" para ejercer el conocimiento, pero le falta adquirir la disposición). Se trata de una "potencia", pero en no en sentido de "materia"16, al ser posible distinguir la actividad desarrollada de la configuración que hace posible que se den las actividades que el ser vivo puede realizar, en tanto ser vivo, porque la actividad podría no estarse realizando, aun cuando ya se cumpla con todas las condiciones para poder realizar la actividad. El alma no es, entonces, las actividades que realiza el ser vivo, sino la configuración del ser vivo que hace posible que se den dichas actividades.

Veamos qué sucede en el análisis del intelecto para comprender mejor a qué se debe la distinción entre dos intelectos. Aristóteles comienza su estudio del intelecto -en de An. III, 4- preguntándose, justamente, "si [el intelecto] es

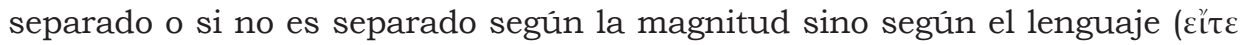

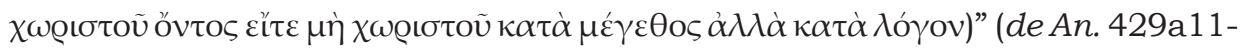
12). Aristóteles parece optar por la segunda posibilidad, que es justamente a la que llamaremos "separabilidad conceptual": una separabilidad que no se da de manera física, sino desde el análisis conceptual que se hace mediante el lenguaje y que se hace de manera análoga a como en una sustancia se puede "separar" materia de forma. Es una distinción que no se da "según la magnitud

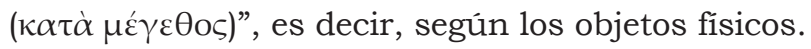

Aristóteles inicia este capítulo y toda su discusión sobre el intelecto (de An. III, 4-8) haciendo un paralelo con respecto a la actividad de percibir. Llega, de esta manera, a una primera conclusión respecto del intelecto: "Ahora bien, si inteligir es como percibir, entonces sería como ser afectado por lo inteligible o algo de tal clase. Por consiguiente, es preciso que [el intelecto], por ser impasible, sea capaz de recibir las formas, i.e., sea en potencia tal como las formas, pero sin que sea [la forma] misma, y de igual manera, será la sensación con relación a lo sensible como el intelecto a lo inteligible" (de An. 429a13-18) ${ }^{17}$.

\footnotetext{
${ }^{16}$ Así lo reconoce Hamlyn, quien a propósito de este pasaje afirma "Aristotle's unwillingness here to introduce technical terminology is noteworthy" (Hamlyn, D.W., (trad.), Aristotle - De Anima Books II and III, Oxford: Oxford University Press, 1993, p. 103). Johansen aclara mejor este punto: "While Aristotle could not consistently refer to the dunamis of the sleeping mathematician as being in energeia, he can refer to it is being in entelekheia, because this term indicates a state of completion relative to another state, which may be another potentiality at a lower level of completion" (Johansen, T.K., The Powers of Aristotle's Soul, Oxford: Oxford University Press, 2012 , p. 23). Así, las potencialidades -o capacidades- del alma son actualidades con respecto a la materia de la que está compuesto el cuerpo, pero con respecto a las actividades mismas que el ser vivo es capaz de desarrollar, son, más bien, potencias.

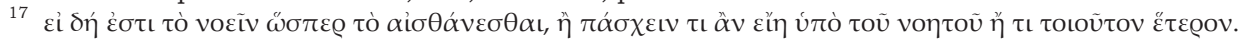

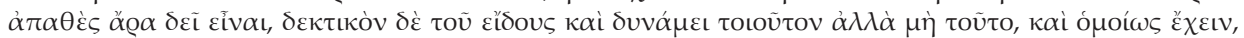

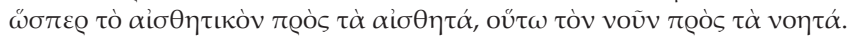


En la psicología aristotélica, es importante esta analogía entre la sensa-

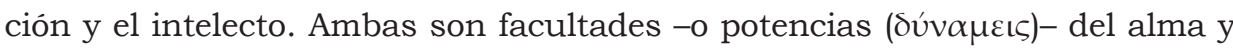
tienen, tal como lo muestra aquí Aristóteles, características similares ${ }^{18}$. Tenemos en ambos casos una capacidad o potencia (el intelecto y la percepción); además, paralelo a esto, tenemos una actividad (inteligir y percibir) y, a continuación, tenemos lo que se podría denominar sus "objetos" que, en el caso del intelecto, son solamente lo que podriamos denominar "objetos inteligibles" o formas separadas de la materia. Pero en el otro caso se trata de los objetos sensibles, que son compuestos de materia y de forma.

De la misma manera, el que "intelige" en potencia es porque tiene la capacidad de inteligir -como el que sabe matemáticas porque ha aprendido, pero no está efectuando ningún cálculo-, mientras que el que intelige en acto es porque de facto está realizando cálculos. Sin embargo, entre intelecto y percepción hay dos diferencias fundamentales en cuanto a los "objetos". En el caso de los sensibles, se trata de objetos "externos ( $\varepsilon \xi \omega \theta \varepsilon v$ )" al sujeto que percibe (de An. 417b20), mientras que, en el caso de la intelección, el objeto es "interno". Según Aristóteles, "la causa es que la percepción en acto es de los particulares, mientras que el conocimiento es de lo universal, y este está de

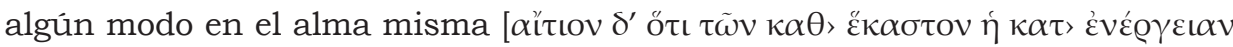

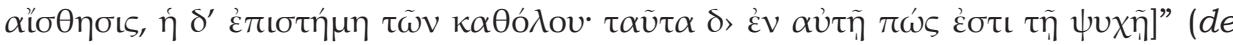
An. 417b21-23). Hay un punto que vale la pena resaltar, a saber, el hecho de que los universales estén de alguna manera en el alma misma. ¿Cómo es esto posible? Lo que pretendemos responder es que es posible, justamente, en la medida en que hay un "intelecto que 'crea' todas las cosas (en tanto formas inteligibles, no en tanto sensibles)"19 y que está en el alma misma (es decir, no es otra entidad diferente o exterior al ser humano mismo).

Así, al poner a los universales de cierto modo ( $\pi \omega \dot{\omega} \varsigma)$ en el alma misma, Aristóteles evita el problema de la ontología dualista platónica, pues los objetos de la percepción son a su vez objetos percibidos y objetos inteligidos y no se

\footnotetext{
18 Seguimos en líneas generales la reconstrucción de este paralelo que hace Burnyeat, M.F., Aristotle's Divine Intellect, pp. 20-21; si bien nos parece sumamente problemática su tesis de la identidad con respecto a la percepción, según la cual cuando alguien percibe algo rojo, el ojo mismo se torna rojo. Es bien discutible llevar tan lejos la analogía o el paralelo que hay entre percepción e intelecto. Si bien, más allá de eso, una discusión más detallada de esta analogía queda por fuera de nuestra discusión actual. En este punto preferimos la interpretación de Johansen, T.K., The Powers of Aristotle's Soul, pp. 228-229.

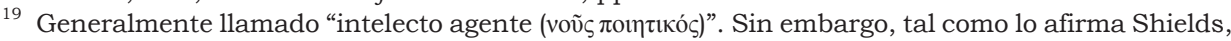
Ch., Aristotle. De Anima. Trad. \& Notes, p. 312, esta expresión no es usada por Aristóteles aquí ni aparece en ninguna otra parte del Corpus. Es Alejandro de Afrodisia quien le da este nombre.
} 
trata, además, de dos naturalezas o dos sustancias diferentes. Son lo mismo, pero su conexión con el alma se da de dos maneras distintas: una física, con la percepción, y otra puramente intelectual, por medio de la intelección de la forma. ¿De qué modo no están los universales en el alma misma? La respuesta más simple y económica para la teoría aristotélica es que están por fuera, como los objetos perceptibles, y en tanto cada inteligible tiene su origen en un objeto perceptible. Esto hace compatible la postura del intelecto en De Anima con lo que afirma en la parte final de Analiticos Posteriores, en donde afirma que "aunque

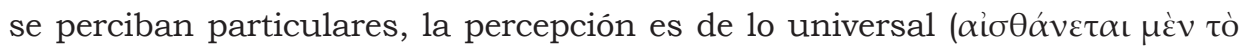

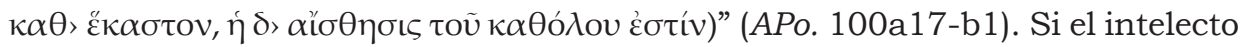
agente crea las formas, no las crea ex nihilo, sino a partir de la percepción. De este modo, tanto los universales como las formas están tanto en los objetos mismos como en las formas, pero solo en tanto los objetos particulares son percibidos e inteligidos. Es esta combinación la que "produce" los universales. Esta conexión entre universales y percepción la veremos con más detalle en secciones posteriores.

\section{b. Los dos intelectos}

Pasemos, entonces, al centro mismo del texto aristotélico que nos interesa. Desde el inicio de de An. III, 5, Aristóteles señala esta capacidad "agente" del intelecto. Dice alli lo siguiente: "Dado que en la naturaleza en su totalidad hay, [i] por una parte, materia para cada género de cosa (esto que en potencia es cada cosa), y [ii] por otra parte lo que es causa; i.e. ${ }^{20}$, es agente, al producir todas las cosas -e.g., la técnica respecto de la materia pasiva-, es necesario que esta misma distinción se dé también en el alma" (de An. 430a10-14) ${ }^{21}$.

El inicio del capítulo marca la distinción hilemórfica en la filosofia aristotélica que hemos precisado anteriormente: la distinción entre algo que es meramente potencial y algo que es productor. Por la terminologia utilizada, la distinción parece estar asociada con el hilemorfismo ${ }^{22}$ : (1) hay algo que es materia

\footnotetext{
${ }^{20}$ Optamos por traducir кaì como epexegético, dado que de otra manera habría que suponer una

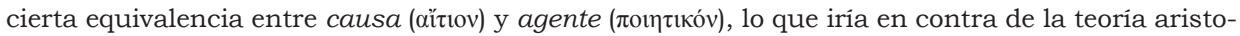
télica de las cuatro causas expuesta en Fisica II, y bastante recurrente en el corpus. Así lo hacen también Boeri, M.D., Aristóteles..., p. 145.

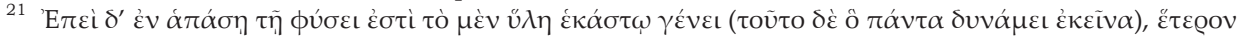

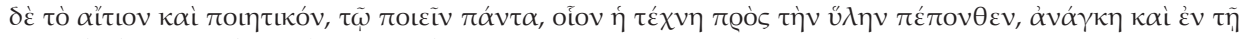

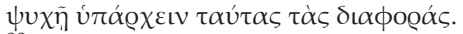

${ }^{22}$ En este punto coinciden la presentación de Boeri, M.D., "Alejandro de Afrodisia como intérprete de la noética aristotélica”, en: Estudios de Filosofia, XL (2009), pp. 79-107; con la de Shields, Ch., Aristotle. De Anima. Trad. \& Notes, pp. 317-318, si bien preferimos el énfasis de este último según el cual se trata de una distinción activo/pasivo más que de materia/forma.
} 


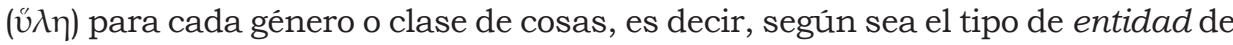
la que estemos hablando, habrá una materia distinta. Cabe señalar que materia parece tener un uso especial en este pasaje, pues, en principio, ni el alma ni el intelecto pueden ser considerados como compuestos con materia. El uso de la expresión materia en este caso parece estar más asociado con su potencialidad en oposición a su actualidad ${ }^{23}$ de la misma manera en que la entelequia primera es, con respecto de la entelequia segunda, materia, pero solo en tanto es en potencia. No obstante, también (2) hay algo que es causa en tanto agente

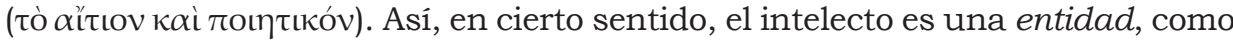
la forma es también, de cierta manera, una entidad (de An. 412a8-9; Metaph. 1017b24-26 y 1029a27-30). No es claro a cuál de las demás causas se está refiriendo Aristóteles (eficiente, formal o final). Sin embargo, es suficiente con tener en cuenta que en contextos naturales -como este- coinciden estas tres causas ${ }^{24}$.

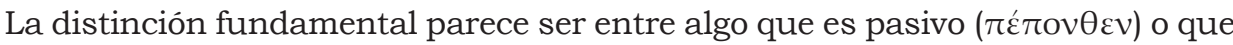

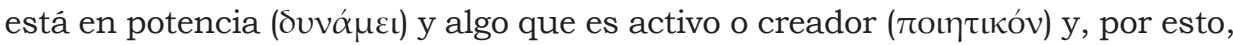
parece caber la distinción entre materia y forma, en cierto sentido no físico o no referido a objetos físicos, los cuales son compuestos de materia y de forma. De esta manera lo entiende Boeri, quien señala que esta es la aplicación del esquema hilemórfico al concepto de voús para dar cuenta de la actualización del intelecto -es decir, el acto mismo de inteligir, en oposición a la capacidad de la intelección-: "Para explicar cómo se produce tal actualización Aristóteles puede simplemente estar recurriendo al esquema hilemórfico y sugerir así que lo pasivo siempre requiere de algo activo para activarse y que, inversamente, lo activo también requiere de algo pasivo para ejercer su actividad. De hecho... eso es lo que claramente indica el mismo Aristóteles en la introducción del capítulo"25.

Así, también habrá en el intelecto algo que sea pasivo y algo que sea activo. Aclaremos mejor qué es lo activo y lo pasivo en la noética aristotélica, pasando al corazón mismo del texto que estamos examinando: "y también hay un intelecto tal porque llega a ser todas las cosas, y otro porque crea todas las cosas, como una cierta disposición -e.g., la luz; en efecto, de cierta manera

\footnotetext{
23 Asociación que hace varias veces Aristóteles (de An. 412a9, 414a16), incluso no siempre refiriéndose a cosas fisicas, sino también a objetos inteligibles (Metaph. 1037a4, 1092a3).

${ }^{24}$ Tal como afirma Aristóteles al final de Física II: "sucede que a menudo tres [de las ausas] confluyen en una sola; en efecto, el qué es y el para lo cual son una única cosa, y lo primero de donde proviene el movimiento es igual en especie a ellos. En efecto, el hombre genera al hombre

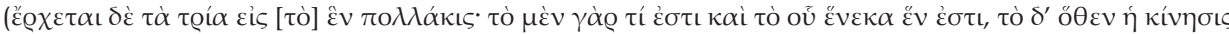

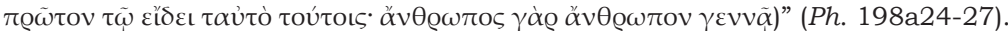

${ }^{25}$ Boeri, M.D., “"Alejandro de Afrodisia como intérprete de la noética aristotélica”, en: Estudios de Filosofia, XL (2009), p. 101.
} 
también la luz hace que los colores en potencia sean colores en actualidad-. Y también así el intelecto es separado, impasible y sin mezcla, siendo actividad en tanto sustancia; en efecto, siempre es más valioso lo que actúa que lo que padece, y el principio [es más valioso] que la materia. Y es lo mismo el conocimiento científico en actualidad que su objeto; pues el [conocimiento científico] en potencia es anterior en el individuo con respecto al tiempo, pero no [es anterior] de manera absoluta en cuanto al tiempo, sino que no sucede que unas veces sí intelige y otras no. Separado es solamente esto mismo que es, y solamente este es inmortal y eterno (aunque no recordamos, porque este [el intelecto activo] es impasible, pero el intelecto pasivo es corruptible); y sin este nada intelige" (de An. 430a14-19) ${ }^{26}$.

Desde el inicio del pasaje se establece la diferencia entre (1) un intelecto que llega a ser todas las cosas ( $\tau \tilde{\omega} \pi \alpha \dot{v} \tau \alpha \gamma^{\prime} \dot{v} \varepsilon \sigma \theta \alpha \mathrm{l}$ ) y (2) uno que crea todas las

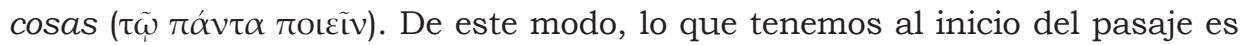
un componente "pasivo", que es transformable y receptivo-de manera análoga a la materia, que es "receptiva" de las formas-y, por otro lado, un componente creador, que es activo, que da la forma. Sin embargo, el intelecto activo no "crea", en sentido estricto, todas las cosas. Lo único que puede crear, en sentido estricto, son objetos inteligibles o formas. Este es un punto de fundamental importancia, pues limita el papel "creador" del intelecto ${ }^{27}$. Además, es preciso señalar que dado el carácter universal que tienen todas las formas, lo que crea el intelecto activo son los universales a partir de la percepción de lo particular ${ }^{28}$. Ahora bien, es

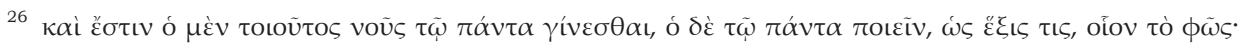

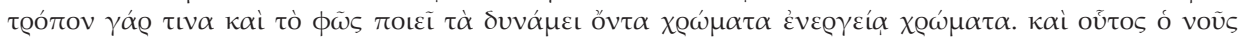

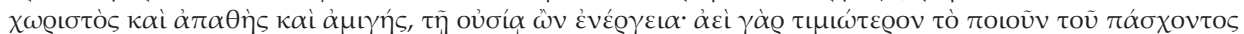

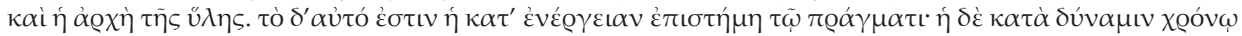

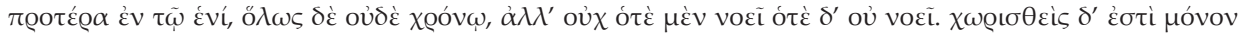

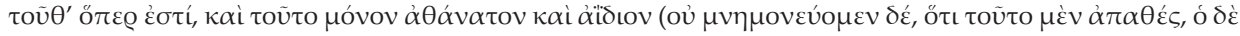

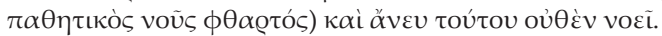

${ }^{27}$ Ya este es un buen indicio para suponer que no se trata de Dios como un creador ex nihilo de todas las cosas -como sucede con el Dios cristiano-. Esta es una razón para suponer por qué Tomás de Aquino no acepta al intelecto agente como Dios (Suma Teológica, I: q79 a4-5). Otro punto por el cual Tomas de Aquino no acepta que el intelecto agente sea el Motor Inmóvil o Dios es que este es, fundamentalmente, causa final, mientras que aquel es, también, causa eficiente. Es bastante dificil hacer coincidir el motor inmóvil con el Dios cristiano, tal como lo ha mostrado ya Bordt, M., "Why Aristotle's God is Not the Unmoved Mover", en: Oxford Studies in Ancient Philosophy, v. XL (2011), pp. 91-109. Para aclarar, aqui tratamos de defender una lectura de lo divino en Aristóteles menos trascendente y más conceptual-normativa, en la cual se deja de lado la lectura que el cristianismo le ha puesto al motor inmóvil lo que ha obligado a que este se diferencie completamente del intelecto activo. De esta manera esperamos ofrecer una reinterpretación del carácter "divino" que Aristóteles les adjudica a estas dos entidades.

${ }^{28}$ Esta es, entre otras, una de las funciones que Aristóteles da al intelecto -y, especialmente, a la inducción- en Analiticos posteriores II, 19. Si bien en el tratamiento del intelecto en de An. parece
} 
claro desde el inicio del texto aristotélico que lo que pretende es establecer una distinción entre un tipo de intelecto activo y un intelecto pasivo. Sin embargo, lo que ha sido largamente discutido es cuál es, en sentido estricto, el alcance de esta distinción. Por una parte, tenemos las interpretaciones "alejandrinas" -por Alejandro de Afrodisia-, según las cuales el motor inmóvil, o "intelecto que se intelige a sí mismo" de Metafisica $\Lambda$, y el intelecto activo son lo mismo: Dios. Esta asimilación fue propuesta por vez primera por Alejandro de Afrodisia (de An. 88-92; 106-113) y discutida y objetada, por primera vez, por Juan Filópono (in de An. 534-535) y, posteriormente, por Tomás de Aquino (Suma Teológica $1: \mathrm{q} 79$ a4-5) ${ }^{29}$.

\section{c. Los fundamentos de la interpretación alejandrina}

Revisemos brevemente los pasajes en los cuales la interpretación alejandrina -o del Intelecto Divino- parece tener un fundamento y, del mismo modo, las criticas que hace su contraparte, la "separación funcional"30 -o Intelecto Humano ${ }^{31}$ - para examinar, seguidamente, cada una de las opciones. Por una parte, tenemos la opción según la cual el intelecto activo es el motor inmóvil y, por lo tanto, Dios. Esta posibilidad tiene la ventaja de explicar prácticamente todas las características que Aristóteles atribuye al intelecto activo. Como enuncia Caston ${ }^{32}$, las características del intelecto que son similares o iguales a las del motor inmóvil son:

haber un salto entre este y la sensibilidad, es necesario resaltar que todas las analogias que Aristóteles establece entre uno y otro muestran que hay una conexión mucho más cercana entre estos, tal como se evidencia en el pasaje final de APo. Aunque la terminología entre uno y otro texto no cuadran muy bien -en de An. no aparece la inducción, y en APo no aparece la distinción entre dos tipos de intelecto-, en ambos casos se pretende explicar el surgimiento de las formas inteligibles. De hecho, lo que se intenta alcanzar con la inducción no son simplemente las formas inteligibles, sino los principios. Sin embargo, tanto formas como principios comparten una característica fundamental: se trata de universales. Más aun, cuando Aristóteles continúa su recuento de la adquisición de los principios, afirma que "aunque se perciban particulares, la percepción es de lo universal" (APo. 100a17-b1). Una similitud importante entre estos pasajes es que en ambos Aristóteles se refiere al intelecto como una disposición (عُ乡ı)), tal como también lo hace en Ética Nicomaquea VI y como lo ha resaltado muy bien Berti, E., "Aristotle's Nous Poietikos: Another Modest Proposal", pp. 8-9.

${ }^{29}$ El rechazo de la interpretación alejandrina que hace Tomás ha sido frecuentemente aceptado; en el siglo pasado esta interpretación fue atacada también por Ross, W.D., Aristotle. De Anima, Edited with Introduction and Commentary, pp. 41-18, y más recientemente, precisamente por Boeri, M.D., "Alejandro...”.

${ }^{30}$ Como la llaman tanto Caston, V., "Aristotle's Two Intellects: A Modest Proposal”, p. 202, como Boeri, M.D., "Alejandro...", p. 100. Plutarco de Atenas fue el primero en proponer, no que se tratara de dos intelectos, sino de dos aspectos o funciones del mismo intelecto, según lo menciona Filópono (in de An. 535.13-16, 536.2-5).

${ }^{31}$ Como la llama más recientemente Shields, Ch., Aristotle. De Anima. Trad. \& Notes, pp. 312-329.

32 Caston, V., “Aristotle's Two Intellects: A Modest Proposal”, pp. 211-212. 
Intelecto activo (De Anima)

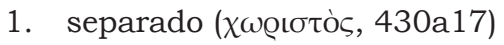

2. impasible $(\dot{\alpha} \pi \alpha \theta \dot{\eta} \varsigma$, a18)

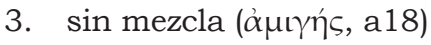

4. actualidad en tanto sustancia ( $\tau \tilde{\eta}$ )

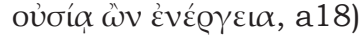

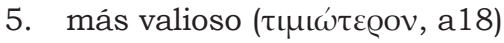

6. es lo mismo que su objeto ( $\tau$ ò

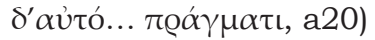

7. de manera absoluta es anterior al intelecto en potencia $(\eta \dot{\eta} \delta \dot{\varepsilon} \kappa \alpha \tau \dot{\alpha}$

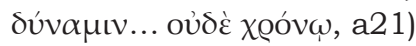

8. intelige ininterrumpidamente (oủ $\chi$

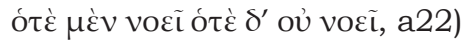

9. es solamente esto mismo que [esen-

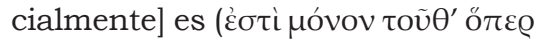

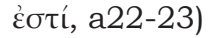

10. solamente este es inmortal y eterno

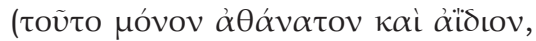
a23)

11. condición necesaria de toda intelec-

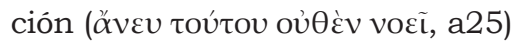

\section{Motor inmóvil (Metafísica)}

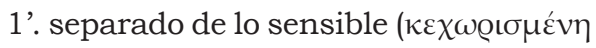
$\tau \tilde{\omega} \nu \alpha i \sigma \theta \eta \tau \tilde{\omega} v, 1073 a 4)$

2'. impasible e inalterable ( $\dot{\alpha} \pi \alpha \theta \dot{\varepsilon} \varsigma \kappa \alpha \grave{\imath}$

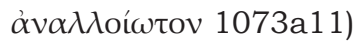

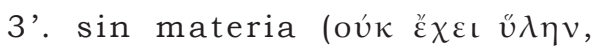
1074a33-34)

4'. actualidad ('̇vé $\gamma \varepsilon\llcorner\alpha$ oũo $\alpha, 1072 \mathrm{a} 25-$ 26, b27-28)

5'. lo más valioso (

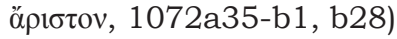

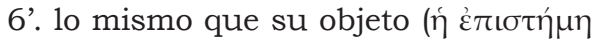

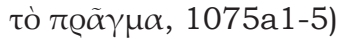

7'. anterior en el tiempo a la capacidad (1072b25; cf. 1072b30-1073a3)

8'. intelige eternamente ( $\tau$ òv $\alpha \check{\pi} \pi \nu \tau \alpha \alpha$ $\alpha \hat{i} \tilde{\omega} v \alpha, 1075 a 10)$

9'. su esencia es inteligir (1075al-5; cf. 1074a33-34)

10'. eterno (áítov $1072 \mathrm{a} 25,1073 \mathrm{a} 4)$

11'. condición necesaria de todo (1072b13-14; cf. 1075b24-26)

La asimilación del intelecto agente con el motor inmóvil permite, por lo tanto, explicar la aparición, en ambos contextos, de todos estos conceptos asociados y, como bien lo señala Caston, permite realizar la explicación más sencilla del intelecto activo: "it is, exegetically, the simplest and most economical reading I know"33.

Sin embargo, como ya lo ha señalado Boeri, el mayor problema de la interpretación alejandrina es que, de aceptarla de esta manera tan "simple", no se estaría hablando de un intelecto humano, sino divino, pero "el intelecto agente aristotélico es una forma que se da en una materia, de donde debe

${ }^{33}$ Ibid., p. 202.

ARETÉ Revista de Filosofía, vol. XXXI, N 1, 2019 / ISSN 1016-913X 
seguirse que como cualquier otra forma 'materializada' debe también destruirse cuando el compuesto se disuelve (este es un presupuesto que se encuentra a la base del argumento de Aristóteles en contra de la supervivencia del alma tras la disolución del compuesto en de An. II 4). Si esta interpretación es plausible, Alejandro no solo estaría pasando por alto el sentido de la distinción intelecto paciente-intelecto agente en Aristóteles, sino que además estaría violando su propia prescripción de que ninguna forma materializada puede subsistir independientemente del compuesto"34.

Así, el problema que señala Boeri apunta, en última instancia, a que si el intelecto activo es Dios, entonces este intelecto activo no podría ser considerado como entelequia primera de cuerpo alguno y, por lo tanto, no haría parte ni sería la forma de compuesto alguno. El problema con esto es que Aristóteles señala que la distinción intelecto activo-intelecto pasivo es una distinción propia

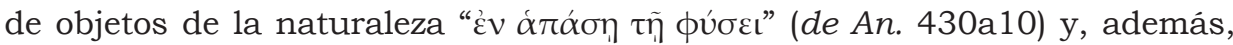

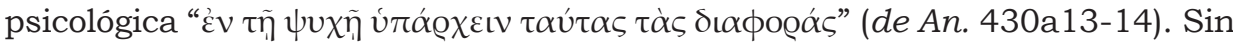
embargo, el motor inmóvil no es, en sentido estricto, una entidad física o que esté dentro de la naturaleza, sino metafisica en tanto que es inmaterial y separada.

La opción que propone Boeri -la opción tomasina o del Intelecto Humanoparece más viable, principalmente, en términos metafisicos. Si el motor inmóvil fuera el intelecto agente, Aristóteles estaría cometiendo un craso yerro metafísico, pues estaría diciendo que el ser humano, en tanto ser físico al cual se le atribuye el intelecto activo, sería al mismo tiempo dos entidades distintas: él mismo -en tanto compuesto- y Dios ${ }^{35}$. Sin embargo, si nos quedamos con que la distinción intelecto activo-intelecto pasivo es una aplicación del modelo hilemórfico de explicación -según la cual se trata de dos funciones del mismo intelecto-, no tenemos cómo explicar dos características fundamentales de este, justamente, las que están asociadas con la divinidad: el hecho de que

\footnotetext{
${ }^{34}$ Boeri, M.D., "Alejandro de Afrodisia como intérprete de la noética aristotélica”, en: Estudios de Filosofía, XL (2009), p. 94.

${ }^{35}$ Hay una tercera propuesta, de origen principalmente averroísta: el intelecto activo no es Dios, pero sí es divino y separado del intelecto pasivo, o intelecto humano, tal como lo presenta Brentano, F., "Nous poiētikos: Survey of Earlier Interpretations", en: Nussbaum, M. y A.O. Rorty (eds.), Essays on Aristotle's De Anima, Oxford: Oxford University Press, 1992, pp. 313-342. Entre los contemporáneos hay una opción similar, propuesta por Kosman, L.A., "What does the Maker Mind Make?", en: Nussbaum, C. y A.O. Rorty (eds.), Essays on Aristotle's De Anima, Oxford: Oxford University Press, 1992, pp. 343-358. También está la propuesta de Berti, E., "Aristotle's Nous Poietikos: Another Modest Proposal", quien intenta mostrar la diferencia entre su posición y la de Averroes. Sin embargo, estas opciones intermedias, en la medida en que reconozcan la separación ontológica del intelecto activo, tienen el mismo problema que la interpretación de Alejandro de Afrodisia: si hay separación, entonces un ser humano sería, al mismo tiempo, dos sustancias.
} 


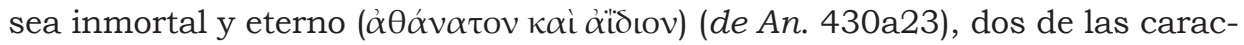
terísticas con las que se relaciona al intelecto activo con el motor inmóvil. Ahora bien, Aristóteles es enfático: solamente este es inmortal y eterno (

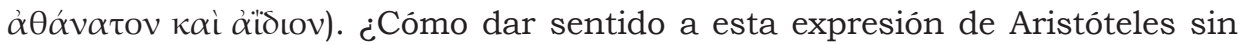
aceptar que el intelecto agente es el mismo motor inmóvil?

Queremos centrarnos en ver la posibilidad de combinar dos tesis que parecen, de entrada, insostenibles en la noética aristotélica. La primera de ellas es que el intelecto activo es una entidad fisica y psicológica-y que, por lo tanto, es parte o función fundamental de cierto tipo de seres vivos: los humanos-, pero también que, pese a estas características, es inmortal y divino. ¿Cómo hacer compatibles estas dos características del intelecto activo?

No son solo estos dos pasajes en los que se presentan sistemáticamente estas características. El mismo argumento que da Caston para identificar el intelecto activo con el motor inmóvil también podría ser aplicado para la felicidad primera de la Ética Nicomaquea. Características similares a las que señalábamos hace un momento también se dan en dicha felicidad:

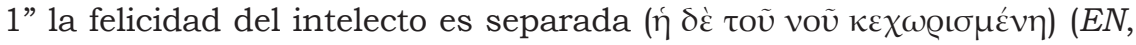
1178a22)

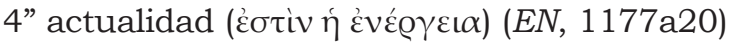

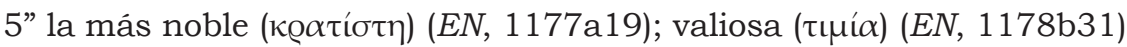

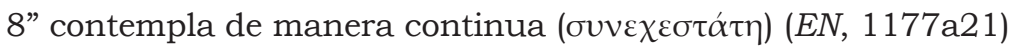

10" divina (Өcĩov òv) (EN, 1177a15).

El argumento utilizado por Caston serviría para probar, por lo tanto, que el intelecto activo, el motor inmóvil y el intelecto cuya actividad es la felicidad primera son lo mismo. Sin embargo, si hay problemas con la relación entre los primeros dos, añadir este tercer elemento, proveniente de la ética, puede ser aun más problemático. No obstante, dar una interpretación que permita mostrar que estos tres conceptos refieren a lo mismo podría mostrar una coherencia bastante significativa en la obra aristotélica. En la sección 3.4, nos centraremos en el concepto que, a nuestra consideración, es el más problemático en toda la propuesta aristotélica y que, como hemos mostrado, aparece en los pasajes decisivos en los que se aclaran estos tres conceptos. Se trata del concepto de "separabilidad". 


\section{d. La "separabilidad" del intelecto activo}

Volvamos a un concepto que hemos discutido desde el comienzo del presente artículo y cuyo significado está en juego, justamente, en la relación entre las dos interpretaciones aparentemente contradictorias: la separabilidad. En principio, si es posible aplicar el mismo significado a esta noción en los tres casos, entonces podríamos tener indicios significativos de que Aristóteles se está refiriendo a lo mismo.

De acuerdo con Miller ${ }^{36}$, cuando Aristóteles utiliza la expresión separado

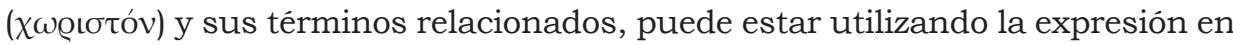
cuatro sentidos distintos:

1. Separación espacial: separación en cuanto al lugar ( la magnitud ( $\mu \varepsilon \dot{\gamma} \varepsilon \theta \varepsilon \iota)$. Es la separación en sentido literal de la palabra, dado que $\chi \omega ́ \varrho \alpha$ significa espacio.

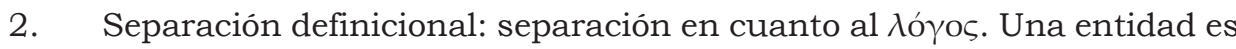
definida sin relación a otra, son entonces separadas la una de la otra. Como Miller aclara, la separación definicional se puede dar sin que se dé la separación espacial, como es el ejemplo de lo cóncavo y lo convexo. Ambos se definen de manera independiente, pero en términos espaciales son inseparables (EN, 1102a26-32; de An. 433b23; Ph. 222b3).

3. Separación ontológica: se refiere por lo general a la separación de las sustancias. Así, $X$ es separado (o separable) de $Y$ en tanto $X$ puede existir sin que $Y$ exista. Así, por ejemplo, los ojos no son separables del ser vivo, porque una vez muerto, los ojos no existen a no ser por "homonimia" (Metaph. 1035b23-24).

4. Separación taxonómica: se refiera a la separación entre facultades o capacidades en los seres vivos, lo que da lugar a la clasificación de estos. Es el caso de ciertos animales que tienen el tacto, pero no tienen los demás sentidos (de An. 434a1).

Caston $^{37}$, por su parte, considera que la separación del intelecto activo es una separación taxonómica. Sin embargo, esta acepción de separabilidad no sería interesante para el caso del intelecto. Dado que la separación taxonómica se refiere fundamentalmente a la separación entre capacidades de los seres vivos, es posible afirmar que cada capacidad se encuentra, de cierta manera,

\footnotetext{
${ }^{36}$ Miller, F.D.Jr., "Aristotle on the Separability of Mind”, pp. 306-339.

37 Caston, V., “Aristotle's Two Intellects: A Modest Proposal”, p. 210.
} 
separada de las demás. Así, la vista se encuentra separada del tacto, dado que no hay ningún impedimento en que una persona invidente pueda palpar. El asunto relevante de la separabilidad, como bien lo señala el mismo Miller ${ }^{38}$ es la separabilidad que hay entre el intelecto activo y todas las otras capacidades que tiene el ser humano. En última instancia, lo importante no es su separabilidad de las demás capacidades, sino del cuerpo en general -razón por la cual Aristóteles afirma que el intelecto no tiene un órgano específico (de An. 429a27)-. Esta es la separabilidad relevante para el caso del intelecto y por la que se pregunta Aristóteles en el inicio del De Anima (403a3-12).

Ahora bien, lo que prueba Miller es que esta separabilidad no puede ser ontológica básicamente por las mismas razones que no se pueden separar la materia de la forma -ontológicamente hablando- en una sustancia natural: se atacaría contra el principio hilemorfista y una misma sustancia resultaría siendo dos sustancias diferentes. De hecho, una de las características del intelecto es conocer las esencias y las formas, pero la forma y la esencia no son separables -ontológicamente- del compuesto. Cuando se plantea la separación materiaforma, esta separación es siempre y necesariamente conceptual, pero nunca ontológica, pues "el intelecto en cuanto actualidad son sus objetos (ó voũ

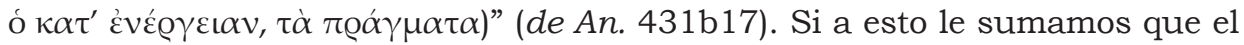

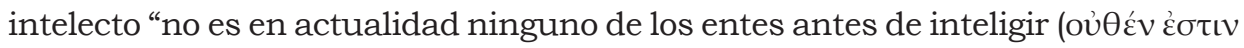

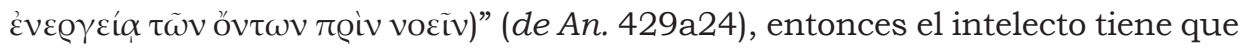
tener el mismo estatus ontológico de lo que intelige, es decir, las formas. Pero si las formas no son ontológicamente separables de la materia, de la misma manera el intelecto no podría ser separable ontológicamente del ser vivo -o ser humano-, sino que sería separable solamente como concepto.

De hecho, la única mención que hace Aristóteles respecto de que el intelecto pueda inteligir algo absolutamente separado de la materia, lo hace al final de de An. III, 7 -dos capítulos después de la discusión del intelecto agente- en donde afirma que "si acaso es posible inteligir algo de lo que está separado siendo este [el intelecto] no separado espacialmente, lo investigaremos posteriormente

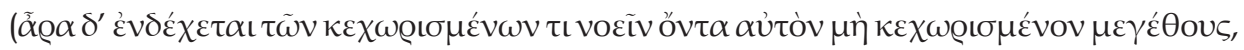

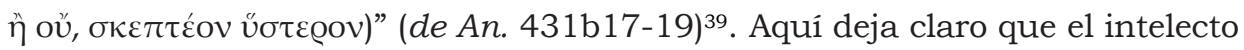

\footnotetext{
38 Miller, F.D.Jr., "Aristotle on the Separability of Mind", p. 311-312.

39 El acuerdo generalizado es que esta investigación nunca se llevó a cabo, tal como lo afirman Hicks, R.D., Aristotle De Anima, with Translation, Introduction and Notes, Cambridge: Cambridge University Press, 1907, p. 542, y Ross, W.D., Aristotle. De Anima, Edited with Introduction and Commentary, p. 308. Sin embargo, Polansky, R., Aristotle's De Anima, Cambridge: Cambridge University Press, 2007, p. 493, y Miller, F.D.Jr., "Aristotle on the Separability of Mind”, p. 327,
} 
que ha presentado en todo el De Anima es "no separado espacialmente ( $\mu$ ì

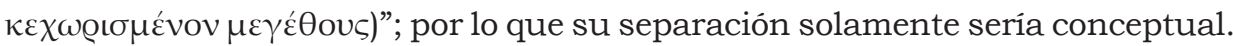
Esto último parece dejar en evidencia que el intelecto activo es, específicamente, el intelecto humano y que es ontológicamente inseparable de la materia (y de las afecciones del cuerpo).

Sin embargo, todavía nos queda un par de características por explicar. ¿Por qué dice Aristóteles que este intelecto humano es divino, inmortaly eterno? ¿Qué quiere decir que solamente este sea inmortal y eterno? Para responder a estas interrogantes quisiéramos presentar una interpretación deflacionaria de la divinidad -para utilizar una terminología similar a la que utiliza Boeri con respecto al intelecto agente ${ }^{40}-\mathrm{y}$ defender esta interpretación por las mismas razones que da Boeri: Dios -o lo divino, inmortal y eterno- no es más que el

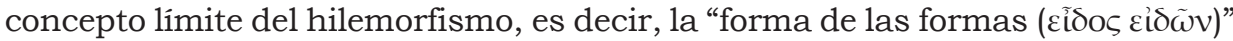
(de An. 432a2). Detrás de esta expresión aristotélica, un poco metafórica, se esconde un supuesto que queremos revelar: que el modelo hilemórfico de explicación también se puede aplicar a las formas mismas. Es así que toda forma y esencia tiene, a su vez, una forma (que se expresa en definición); tal forma es el intelecto agente. Ahora bien, este intelecto, en la medida en que es forma de formas, es el que "crea" las formas, es decir, es condición necesaria de que haya tales formas $y$ esencias de sustancias particulares, sobre todo en tanto inteligibles.

Hemos señalado, hasta el momento, que la "separación" del intelecto con respecto al cuerpo es una separación que se puede dar solamente en términos conceptuales y no en términos ontológicos. Sin embargo, para probar completamente este punto, es necesario que la "separación" de la divinidad

sospechan que esta investigación es la que se lleva a cabo en la Metafísica, especialmente en el libro XII. Al mostrar cómo coinciden los conceptos entre De An. III, 5 y Metaph. XII, 9, hemos intentado mostrar también que en ambos se lleva a cabo una investigación similar, aunque desde puntos de vista distintos. Si el intelecto agente es lo único que es inmortal y eterno, otra entidad con las mismas características haría que se tuviera que estrangular el texto aristotélico para darle sentido a esta expresión.

${ }^{40}$ La propuesta que hace Boeri es hacer una interpretación deflacionaria del intelecto agente, la cual consiste en ver al intelecto agente simplemente como el "factor activo del modelo hilemórfico aplicado a la noética aristotélica" (Boeri, M.D., "Alejandro de Afrodisia como intérprete de la noética aristotélica”, en: Estudios de Filosofia, XL (2009), pp. 97; cf. p. 98 (n. 39) y p. 101. Suponemos que la llama "deflacionaria" porque presenta al intelecto agente como una "parte" inmanente del intelecto, y no como una "parte" trascendente, haciendo que este descienda en la escala ontológica. Lo que queremos mostrar en la siguiente parte de este trabajo es que, si se acepta esta interpretación del intelecto, habría que aplicar la misma interpretación "deflacionaria" al concepto mismo de Dios, pues posterior a este intelecto no habría más escalones ontológicos en la teología aristotélica. Lo que explicaria que el intelecto agente sea llamado "lo único inmortal y eterno". 
con respecto al resto de las formas, en general, se pueda hacer de la misma manera, es decir, de manera conceptual, pero no ontológica. Este último paso en la argumentación nos conducirá, entonces, al motor inmóvil o la divinidad por excelencia en la filosofia aristotélica, para ver alli si es posible comprender esta separación en términos conceptuales más que físicos.

\section{El intelecto que se intelige a sí mismo}

Burnyeat ha defendido una interpretación cercana a la de Alejandro de Afrodisia según la cual el intelecto activo y el motor inmóvil son lo mismo. Según Burnyeat, cuando el intelecto está activamente explicándose a sí mismo -en estos pasajes aristotélicos- es la Divinidad explicándose a sí misma ${ }^{41}$. Para sostener esta interpretación, Burnyeat afirma que tanto el intelecto activo como el pasivo son sistemas de conceptos, pero, a diferencia del segundo, -humano e imperfecto-, "the divine intellect is a system (better, perhaps, the system) of absolutely correct concepts"42. El hecho de que tanto el intelecto activo como el pasivo sean considerados como sistemas de conceptos es fundamental para mantener la distinción intelecto activo-intelecto pasivo en términos hilemórficos. En este punto, Burnyeat coincide con Berti, quien afirma que "intellect is the habit of the principles"43, tal como afirma Aristóteles también en Analiticos Posteriores II, 19 y en Ética Nicomaquea VI, 6: "it is the patrimony of eternal truths that humanity has gradually discovered and that it will continue to discover, a patrimony that, once learnt by the single individual, becomes the actual intellect of the individual, i.e. the acquired intellect"44.

Claramente, tanto la tesis de Burnyeat como la de Berti difieren de la tesis de Alejandro de Afrodisia en tanto para estos el intelecto agente tiene un carácter específicamente conceptual. Se trata del sistema de conceptos -más aun, de principios- que son descubiertos por el intelecto pasivo ${ }^{45}$-o intelecto humano, según estos autores-. Ahora bien, lo que intentaremos defender es que

\footnotetext{
41 Burnyeat, M.F., Aristotle's Divine Intellect, p. 9.

42 Ibid, pp. 40-41.

43 Ibid., p. 9.

44 Ibid.

45 Berti no está de acuerdo con la posición de Burnyeat y en general con la de Alejandro de Afrodisia, porque para él, al hablar de un "sistema de conceptos" no se está hablando explícitamente de una entidad, ni menos aun de una entidad metafísica de las características de Dios. Creemos, en todo caso, que la idea de Dios de Berti es la tomasina, y esta es justamente la idea de Dios que consideramos no es la más adecuada para entender la noética aristotélica y, si nuestras conclusiones son acertadas, tampoco su metafisica.
} 
este carácter conceptual del intelecto divino es lo que permitirá mostrar que la distinción entre intelecto activo e intelecto pasivo es una distinción conceptual pero no una distinción ontológica, lo que hace incluso tener que replantear la discusión con respecto a si el intelecto agente es externo al ser humano. $\mathrm{Si}$ la distinción entre dos tipos de intelecto es puramente conceptual -pero no fisica u ontológica- hablar de un intelecto "externo" pierde todo sentido y pasa a convertirse, más bien, en un error categorial. Con esto estaremos evitando el dualismo ontológico del intelecto, pero al mismo tiempo explicando por qué Aristóteles caracteriza al intelecto agente como "divinidad". Así, lo divino es un aspecto de la naturaleza en tanto forma del universo, es decir, su aspecto formal o conceptual, pero, además, en tanto concepto normativo, en tanto causa de las formas. En la medida en que lo formal-normativo no es un compuesto de materia y de forma, sino que es estrictamente formal, no puede ser susceptible de ser destruido, lo que lo hace, por lo tanto, divino y eterno (tal vez haya que precisar, más bien, atemporal). Aclaremos esto mejor presentando en qué consiste, para Aristóteles, ser una sustancia inteligible y en qué se distingue de las sustancias sensibles.

\section{a. La sustancia inteligible y las sustancias sensibles}

Para poder comprender a qué se refiere Aristóteles con una "sustancia inteligible", hagamos antes una breve presentación de lo que Aristóteles considera una sustancia sensible. En Metafisica VIII, 1, y a modo de resumen de lo dicho en el libro anterior, Aristóteles dice lo siguiente: "Ahora hablemos acerca de las sustancias comúnmente aceptadas. Estas son las sensibles: y todas las [sustancias] sensibles tienen materia. Así, el sujeto es sustancia, que en un sentido es la materia (y llamo materia a aquello que en acto no es algo determinado, pero en potencia es algo determinado), pero en otro sentido es el enunciado y la figura, que siendo algo determinado es separable según la definición; en tercer lugar, está el compuesto de estas, del cual hay generación y corrupción, y el cual es separado de manera absoluta: en efecto, de las sustancias según el enunciado, unas son separadas, pero otras no" (Metaph. 1042a24-31) ${ }^{46}$.

En este párrafo, tenemos, nuevamente, las tres maneras en las que se dice sustancia: la materia, la forma y el compuesto. Además, tenemos la misma

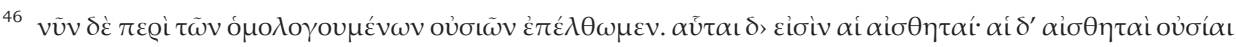

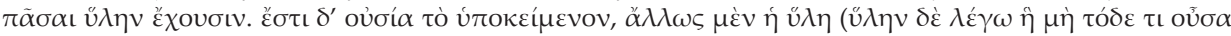

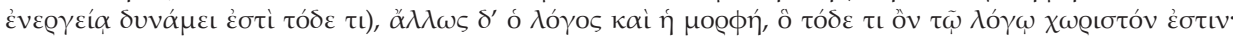

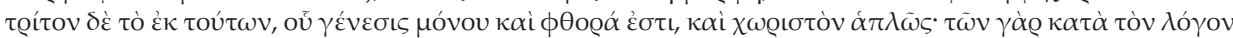

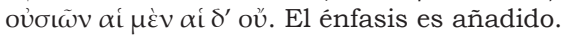


característica con respecto de la forma que habiamos hecho notar antes: es

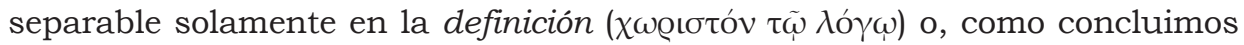
anteriormente, es separable conceptualmente, y esto en razón de que solamente el compuesto es separable en sentido estricto ( $\chi \omega \varrho \iota \sigma \tau o ̀ v ~ \alpha ́ \alpha \lambda \tilde{\omega} \varsigma$ ).

Sin embargo, pese a que en estos pasajes se insiste en que la forma solamente es separable en tanto enunciado -o definición, o concepto- Aristóteles emprende en Metafísica XII, 6, una investigación acerca de la sustancia inmóvil. Generalmente se ha problematizado sobre la relación que hay entre este libro y los libros dedicados a la sustancia (VII-IX) ${ }^{47}$. No es nuestro interés por ahora resolver este problema, pero sí pretendemos arrojar algunas luces con respecto a la continuidad del proyecto llevado a cabo en la Metafisica. Precisamente las luces que queremos arrojar suponen, de entrada, que el tratamiento de la sustancia sigue siendo un tratamiento conceptual. Sin embargo, el trasfondo teológico que aparece en el libro XII tiene que ver con que Aristóteles está haciendo, ahora, un análisis del concepto de sustancia, pero en tanto sustancia, y que este análisis lo lleva a concluir que este concepto de sustancia es principio y condición de posibilidad de todos los demás conceptos y, en consecuencia, de todas las demás sustancias. Esto quiere decir que la materia y la forma, que son lo que "compone" a la sustancia en tanto compuesto, tienen una característica fundamental: a diferencia del compuesto, son inengendrados e incorruptibles. Se transforma el compuesto, pero tanto la materia como la forma son intransformables. Por lo tanto, decir que se transforman sería cometer un error categorial, ya que estos son atemporales. ¿A qué se debe esta característica de atemporalidad? Si nuestra interpretación es acertada, se debe a que la causa formal de estos conceptos es, a su vez, inengendrada e incorruptible y, por lo tanto, eterna. Pero eterno no en tanto exista como sustancia todo el tiempo, sino en tanto su existencia se dé al margen de lo temporal, de lo físico (por lo que sería más precisa la expresión atemporal que la expresión eterno, que hace pensar en algo que existe como sustancia durante toda la eternidad). No obstante, esta imagen de "aquello que dura toda la eternidad" puede estar desdibujando la idea de que para Aristóteles los conceptos tanto de materia como de forma no sean susceptibles a las vicisitudes del tiempo, entre ellas la generación y la destrucción. En Metaph. XII lo que pretende hacer Aristóteles es determinar el origen y la razón por la cual estos principios tienen estas

\footnotetext{
47 Hay un recuento de este problema, y de sus principales intentos de solución, en Wedin, M., "The Science and Axioms of Being", en: Anagnostopoulos, E. (ed.), A Companion to Aristotle, Londres: Wiley-Blackwell, 2009, pp. 137-141.
} 
características divinas y atemporales. Esto es lo que va a conducir a Aristóteles a la teología, tal como fue anticipado en Metaph. VI, 1.

\section{b. El motor inmóvil}

A continuación, examinaremos algunos de los argumentos con los que Aristóteles intenta probar la existencia de dicha sustancia inmóvil que, a su vez, es la que pone en movimiento las demás sustancias. Estos argumentos nos interesan, pero en la medida en la que van a conducir a la definición del motor inmóvil como lo que "se intelige a sí mismo, ya que es lo más noble, y su

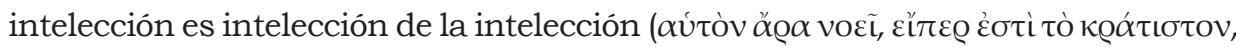

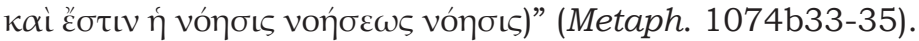

Veamos cómo Aristóteles llega a esta definición de "motor inmóvil”. El primer argumento es el siguiente: "pero, además, si hay algo capaz de mover o de producir, pero que no estuviera actuando, no habría movimiento: en efecto lo que tiene potencia es admisible que no esté actuando. De modo que no habría ningún provecho con colocar sustancias eternas, como los que colocan las Formas, si no hay algún principio de cambio en ellas. Y no sería suficiente con esto, ni con alguna otra sustancia aparte de las Formas; en efecto, si no está en acto, no habrá movimiento; pero tampoco [habrá movimiento] aunque sí se esté en acto, dado que su sustancia será potencia; en efecto, no habrá movimiento eterno, pues es posible que lo que es en potencia no sea el caso. Es preciso, por tanto, que haya algún principio tal que su sustancia sea acto. Además, es preciso que sustancias de tal clase sean inmateriales: en efecto, es preciso que sean eternas, si es que hay algo que pueda ser eterno. [La sustancia de tal clase] es, entonces, en acto" (Metaph. 1071b12-22) ${ }^{48}$.

El argumento parte del hecho básico de que el movimiento es un cambio de la potencia al acto. Ahora bien, a esto es preciso sumarle el hecho de que hay movimiento, es decir, que hay sustancias en potencia y sustancias en acto; las sustancias que están en acto ya se movieron y las que están en potencia se moverán o se podrán mover. Sin embargo, el punto de partida de este argumento es que, si todas las sustancias fueran en potencia, no habria necesidad

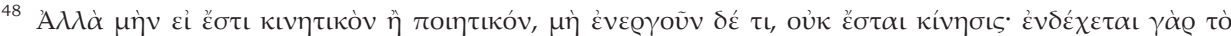

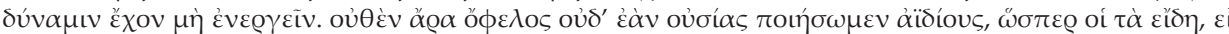

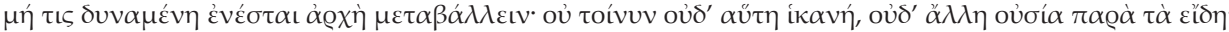

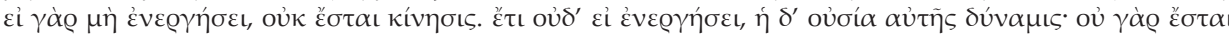

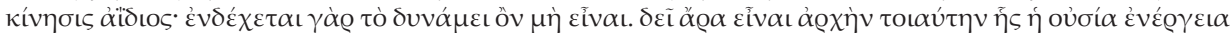

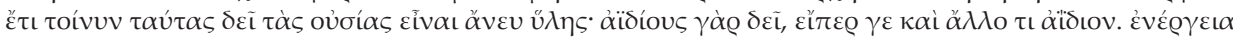

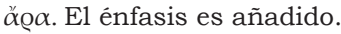


alguna de movimiento. Este es el punto central en el argumento, pues no se quiere probar que haya movimiento, sino que hay una condición básica y necesaria para que haya dicho movimiento. Lo fundamental del argumento es que el principio del cambio no es algo que esté constantemente en potencia -y las razones de Aristóteles son bien explícitas: lo que está en potencia, es admisible que se dé o que no se dé-, así que dicho principio tiene que estar en el estado contrario a la potencia: tiene que estar en acto.

Además, parece natural que el acto tenga prioridad con respecto a la potencia ${ }^{49}$. Si la potencia es como la materia y el acto es como la forma, dado que hay prioridad de la forma con respecto a la materia, habrá, de la misma manera, prioridad del acto con respecto a la potencia. Podemos concluir aquí que la prioridad del acto sobre la potencia es una prioridad conceptual ${ }^{50}$.

La característica principal del primer motor es mencionada posteriormente, cuando se introduce el intelecto. Aristóteles lo introduce de la siguiente manera: "el intelecto se intelige a sí mismo en la medida en que participa de lo inteligible; en efecto, llega a ser inteligible al captar e inteligir, de manera que son lo mismo el intelecto y lo inteligible. En efecto, el intelecto es lo que tiene la capacidad de recibir lo inteligible i.e. la sustancia, pero al tener [la sustancia] está en acto, de modo que el intelecto parece tener lo divino en mayor medida que [lo inteligible], y la contemplación es lo más placentero y lo mejor" (Metaph. $1072 \mathrm{~b} 19-28)^{51}$.

\footnotetext{
49 Como defiende Aristóteles en Metaph. IX, 8, en donde afirma que el acto es anterior que la potencia no solo en términos conceptuales, sino también incluso temporales, pues afirma Aristóteles que "lo que es en acto se genera de lo que es en potencia por la acción de algo que es

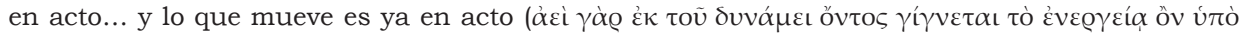

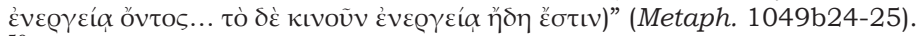

${ }^{50} \mathrm{La}$ prioridad conceptual del acto con respecto a la potencia se hace evidente, principalmente, en Metaph. IX, 8, en donde Aristóteles afirma que el acto es anterior a la potencia en cuanto a

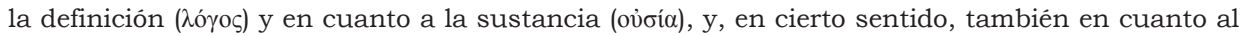
tiempo. Hay prioridad del acto sobre la potencia, en cuanto a la definición, básicamente porque la potencia se define en términos del acto; decir de A que es capaz de " $\chi$ ", o tiene la potencia de " $x$ ", es definido a partir de definir primero " $x$ ". La prioridad sustancial se da en términos de que la sustancia en potencia es materia, pero la sustancia en acto es forma. La prioridad temporal, que es expuesta aquí por primera vez, es expuesta en términos de que todo lo que se genera, se genera a partir de algo y ese algo tiene que ser en acto, no en potencia. Estos tres elementos componen, entonces, lo que hemos denominado prioridad conceptual. Makin, S., Aristotle Metaphysics Book $\Theta$, transl. with introd. \& comm, Oxford: Clarendon Press, 2004, pp. 185-187, señala un paralelo importante que hay entre este argumento y el argumento en Metaph. XII, 6.

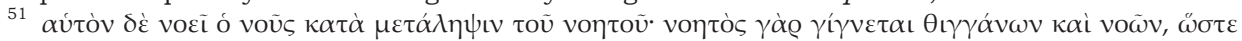

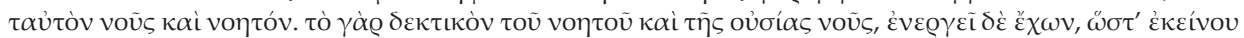

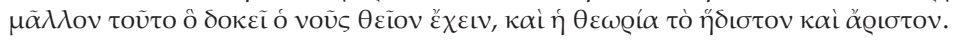


Este párrafo intenta resolver un problema con respecto al estatus del intelecto: ¿es posible inteligir el intelecto mismo? Aristóteles parece estarle huyendo a dos posibilidades. La primera es que el intelecto sea, él mismo, ininteligible. Si es así, habria un problema porque habría algo que es condición necesaria -y causa- de lo inteligible que es ininteligible; si esto es así, lo inteligible no podría ser inteligible. La otra posibilidad es que el intelecto sea inteligido en virtud de otra cosa, así como el compuesto es inteligido en virtud de que tiene cierta forma. Para esta posibilidad habría que suponer algo así como una "forma del intelecto" y por lo tanto un "principio del principio". Si esto es así, el intelecto no podría inteligir ${ }^{52}$. Ahora bien, el intelecto tiene un doble aspecto: es agente y paciente ${ }^{53}$, es decir, es capaz de inteligir, pero al mismo tiempo es inteligido. Aquí Aristóteles aplica los criterios de prioridad -que señalábamos anteriormente al acto y la potencia- pero ahora al intelecto para mostrar en qué medida el intelecto es ese "primer motor". Ya habia probado que el "primer motor" debería estar en acto, y ahora está probando aquí, además, que el intelecto siempre está en acto. La prueba parece sencilla: primero, el intelecto, para poder inteligir, tiene que ser, al mismo tiempo, inteligible. Así, la potencia de inteligir supone el acto de inteligir. De esta manera, el intelecto está en acto todo el tiempo. Este acto del intelecto -la intelección- es el teorizar o la contemplación; de ahí que resulte que es "lo placentero y lo mejor"54. Además de esto, hay una característica importante que cumple el intelecto, dado que basta con sí mismo para llevar a cabo sus actividades -pues basta con que se intelija a sí mismo, para lo cual se basta consigo mismo-, va a cumplir otro de esos requisitos importantes: siempre estará en acto55. Del mismo modo en el

\footnotetext{
52 Aquí aparece un problema similar al del "tercer hombre": algo es en virtud de que se predica de algo distinto. Sin embargo, aun cuando Aristóteles parece aceptar la posibilidad de la autopredicación con respecto a lo inteligible, está mostrando que esta "autopredicación" es distinta a la de las Formas platónicas en varios aspectos, pero el más importante de todos, es que la autopredicación del intelecto es lo que hace posible que se intelijan todas las demás sustancias. El punto que queremos defender con respecto a la autopredicación, es que es hasta la introducción del intelecto como el "principio" de las entidades que se superan los problemas que tenía la ontología platónica, y no, como considera Scaltsas, Th., "Aristotle's 'Second Man'Argument”, en: Phronesis, v. XXXVIII, 2 (1993), pp. 117-13, que se superan en Metafísica VII, 6, cuando Aristóteles se pregunta si una sustancia y su esencia son lo mismo.

53 En este pasaje de Metafisica Aristóteles no hace esta distinción, pero es preciso suponerla

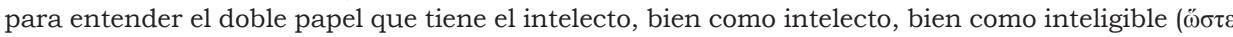

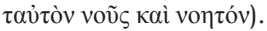

${ }^{54}$ Es en estos mismos términos que Aristóteles va a hablar de la actividad del intelecto como felicidad en EN X, 7: es la mejor actividad de todas porque siempre se está realizando, es decir, siempre está en acto.

55 En términos de la Ética, esta característica es justamente la que va a permitir que el intelecto cumpla con uno de los requisitos fundamentales de la felicidad: la autosuficiencia (EN, 1097b7-
} 
que se percibe cada vez que se tiene un objeto perceptible enfrente, de la misma manera siempre que se tenga un inteligible el intelecto va a inteligir. Así, dado que el intelecto "estará" allí, entonces estará en un constante inteligir56. Este es, justamente, el último paso de la argumentación aristotélica con respecto al motor inmóvil: "se intelige a sí mismo, ya que es lo más noble, y su intelección

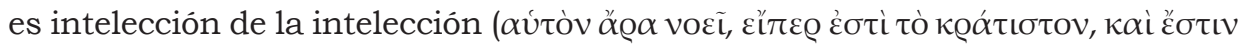

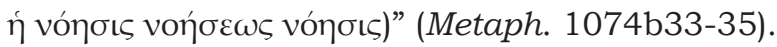

\section{c. Motor inmóvil, materia y forma}

Ahora bien, queda por explicar no solamente la prioridad que tiene el intelecto, sino que, en este caso, se trata de una supremacía. Sin embargo, no se trata en este caso de una supremacia ontológica ${ }^{57}$. De hecho, hablar de supremacía ontológica resulta bastante desorientador, pues pareciera que se estuviera hablando de la "sustancia más sustancia". Es claro que el motor inmóvil, en tanto intelecto que se intelige a sí mismo, es la "sustancia" que se encuentra al final de una serie de conceptos, pero tiene unas características especiales, a diferencia de las demás sustancias (y esto incluye tanto a las sustancias particulares como a la materia y la forma). Podemos afirmar que los conceptos de materia y de forma son conceptos de segundo orden, porque son conceptos que no se refieren directamente a los objetos individuales, sino que se refieren a conceptos de primer orden: la forma, en tanto concepto, se refiere a las formas los objetos determinados, pero no a los objetos mismos. De igual

\footnotetext{
$22 ; 1177 \mathrm{a} 22-\mathrm{b} 1)$.

56 Es preciso resaltar que este "estar" del intelecto mismo es figurativo. El intelecto mismo no "está" en ninguna parte, pues solamente los objetos materiales ocupan espacio. El intelecto es una forma, una potencia del alma, que se activa o se actualiza al inteligir. Pero es potencia en la medida en que depende del acto mismo de inteligir. Esto hace que la distinción entre el intelecto que intelige y el intelecto inteligido sea una distinción conceptual más que física. De igual manera no se da antes el intelecto que el inteligir: la actividad de inteligir tiene prioridad conceptual, pero no temporal. Aplicar conceptos temporales o espaciales al intelecto es, de nuevo, cometer un error categorial.

57 Reeve, C.D.C., Action, Contemplation and Happiness, Cambridge: Harvard University Press, 2012, pp. 15-16, propone una asociación entre este primer motor y el motor que mueve el cielo, que aparece en Metaph. XII. Sin embargo, advierte que hay una diferencia entre este Dios que actúa (intelige) y el Dios que mueve, como afirma Bordt en "Why Aristotle's God is Not the Unmoved Mover". Lo que queremos proponer aquí es que no se trata de un motor, en el sentido de ser una causa eficiente, como propone Judson, L., "Heavenly Motion and the Unmoved Mover", en Gill, M.L. y J.G. Lennox (eds.), Self-Motion: From Aristotle to Newton, Princeton: Princeton University Press, 1994, pp. 156-171, sino en tanto es una condición conceptual necesaria para que sean posibles todas las "causas eficientes" -y de paso todas las demás causas-.
} 
manera sucede con la materia ${ }^{58}$, que es, a su vez, un concepto de segundo orden que se refiere siempre a "conceptos", pero nunca directamente a un objeto o sustancia particular. Estos conceptos de segundo orden conservan cierta prioridad explicativa sobre los conceptos de primer orden, en tanto son aquellos los que definen el estatus ontológico y físico de aquellos, principalmente, en lo que se refiere a su carácter en cualquier explicación de movimiento y transformación que recurra al hilemorfismo.

Adicional a esto, hay también una prioridad de la forma con respecto a la materia, principalmente, porque la forma es la que hace posible, en sentido estricto, los conceptos de primer orden, en tanto el enunciado de la forma de una sustancia determinada es la definición de dicha forma. Aristóteles afirma lo siguiente en Metafisica: "Así pues, hay parte de la forma (y llamo forma a la esencia), y hay parte del compuesto de la forma y la materia misma. Pero las partes del enunciado solamente son los de la forma, y a su vez el enunciado es de lo universal: en efecto son lo mismo el círculo y el ser círculo, y el alma y el ser alma. Pero del compuesto, como de este círculo y de un particular determinado, o sensible o inteligible -y llamo inteligibles, e. g., a los [círculos] de los matemáticos, y sensibles, e. g., a los de bronce o de madera- de estos no hay definición, pero son cognoscibles por la intelección, o por la percepción, y cuando se alejan de la plena realización no es claro si son el caso o no; aun cuando siempre se nombran y se conocen a través de un enunciado universal. Pero la materia es en sí misma incognoscible" (Metaph. 1035b31-6a9) 59 .

\footnotetext{
58 En este punto consideramos que el concepto de "materia" no se refiere en sí a ninguna materia particular determinada, pues en tanto materia es siempre indeterminada, por lo que no hay, para Aristóteles, tal cosa como una "materia prima" o unos "elementos básicos" de la physis. En su comentario a los dos primeros libros de la Física, Charlton, W., Aristotle Physics Books I \& II, Oxford: Oxford University Press, 1970, pp. 129-145, hace un esfuerzo importante por probar que en la física aristotélica no hay tal materia prima. Una crítica importante a la postura de Charlton y una defensa clásica de la materia prima en Aristóteles se encuentra en Robinson, H.M., "Prime matter in Aristotle", en: Phronesis, v. XIX, 2 (1974), pp. 168-188. Una reconstrucción reciente del problema junto con una defensa de la postura de Charlton se encuentra en Lewis, F.A., "What's the Matter with Prime Matter?", en: Oxford Studies in Ancient Philosophy, v. XXXIV (2008), pp. 123-146, posición que seguiremos en lineas generales: "Prime matter is the limiting case of the notion of matter, which applies throughout the sublunary sphere, and is absent only outside the sublunary world altogether, in the case of the Unmoved Mover, which is itself the limiting case of the correlative notion of form. The Unmoved Mover is the limiting case of form, on the usual view, because all engagement with matter is absent from it. Just so, prime matter is the limiting case of matter, because all engagement with form is absent-of all the cases of matter, prime matter alone is not itself a compound of form and matter" (ibid., pp. 127-128).

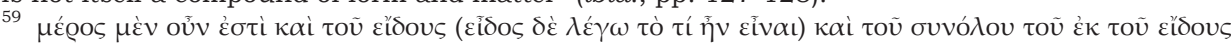

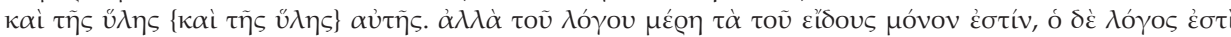

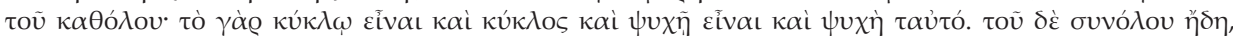

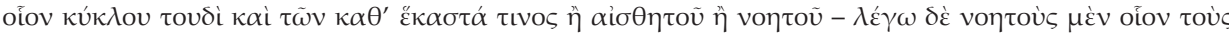


Con la aparición del intelecto se resuelve un problema adicional: de la misma manera que una sustancia particular es incognoscible a menos que pertenezca a una clase de cosas -ya sea género o especie, debido a que no se percibe la materia de la sustancia particular, sino la forma-, de esta misma manera la forma es inteligible, pero la forma inteligible no es suficiente si no hay algo que intelija dicha forma. El intelecto es, para utilizar el último peldaño en la escala, un concepto de tercer orden, dado que es condición de posibilidad de las formas y es, además, quien intelige dichas formas. La forma, en la medida en que es lo definible de un objeto particular, no es exclusiva de un objeto particular, sino de una clase de objetos a la cual dicho particular pertenece; así, la definición es una definición de universales y no de particulares. A esto hay que sumarle un asunto importante: los objetos particulares, las sustancias individuales, solamente se pueden conocer a través de un enunciado universal; esto quiere decir que dicha sustancia es cognoscible, en sentido estricto, solamente en la medida en la que se conoce también su definición ${ }^{60}$.

Es importante señalar el énfasis que hace Aristóteles, nuevamente, con respecto de la incognoscibilidad de la materia, a saber, que, tal como lo habíamos hecho notar ya, en sentido estricto, lo único que se puede conocer de las sustancias individuales es su forma. Aristóteles expresa esto en el $D e$ Anima de la siguiente manera: "Con respecto a la percepción en general es preciso señalar que, por una parte, la percepción es de lo que es capaz de recibir la forma de lo perceptible sin la materia; e. g., la cera recibe la marca del anillo sin el hierro y el oro, atrapando la marca del oro o del bronce, pero no en tanto oro o bronce; de igual manera, también el sentido es afectado por cada cosa que tiene color, sabor o sonido, pero no en tanto se dice que es aquello individual, sino en tanto que es de cierta clase, y en tanto a su enunciado" (de An. 424a17-24) ${ }^{61}$.

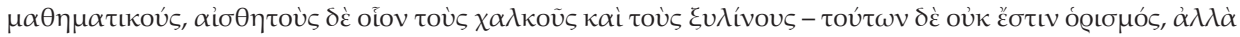

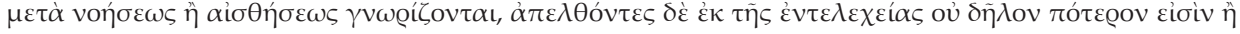

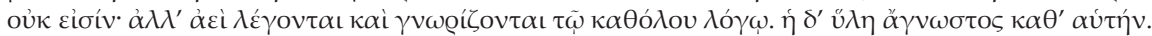

${ }^{60}$ Como señala Charles, este pasaje hace eco del modelo de definición-explicación que aparece en Analiticos Posteriores II, 10-17 (cf. Charles, D., D., "Definition and Explanation in Aristotle's Posterior Analytics and Metaphysics", p. 279).

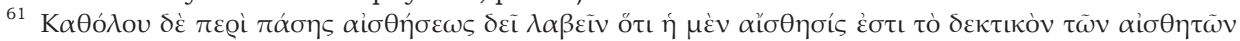

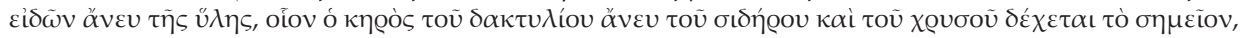

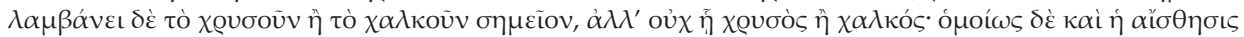

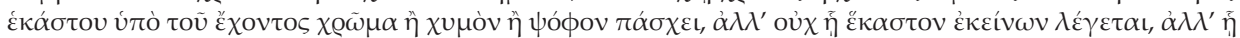

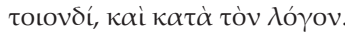


De nuevo, pero ahora con mucho más detalle, el punto con respecto a la materia es que, no solamente es incognoscible, sino que es, además, imperceptible, pues, en sentido estricto, lo que se percibe es la forma del compuesto, pero no su materia. Así, si la forma no es algo que se dé exclusivamente al individuo, sino que la forma se da en él en tanto que dicho individuo pertenece a una clase de cosas, lo que se percibe, al percibir su forma, no es ese individuo en particular, sino que se percibe "en tanto que es de cierta clase"62.

Esto podría servir de vínculo para explicar por qué en Analiticos Posteriores Aristóteles afirma lo siguiente: "a partir de la percepción se origina la memoria, y de la memoria repetida de lo mismo se origina la experiencia. En efecto, muchos recuerdos en número son una sola experiencia. Y a partir de una experiencia, o de todo lo que ha quedado a manera de universal en el alma, (el uno sobre muchos, i.e., lo que es uno y lo mismo para todas aquellas cosas), [se origina] el principio de la técnica y del conocimiento científico" (APo. 100a3-8) ${ }^{63}$.

En este pasaje, Aristóteles estaría dando cuenta de cómo, a partir de la percepción, se alcanzan los "principios de la técnica y del conocimiento científico". En términos de Metafísica, lo que estaría sucediendo es, al llegar a los principios, se llega al punto de una definición de una sustancia particular. Lo que estaría explicando Aristóteles en este pasaje es cómo es posible adquirir los conceptos de primer orden, es decir, los conceptos que se refieren directamente a las sustancias particulares, por lo general, a manera de definiciones de los universales a los cuales pertenecen dichas sustancias particulares ${ }^{64}$. Así, Aristóteles explica

\footnotetext{
62 Este pasaje ha sido el centro de un debate con respecto a si la percepción en Aristóteles es un proceso físico o fisiológico -posición propuesta originalmente por Sorabji, R., "Body and Soul in Aristotle", en: Philosophy, v. XLIX, 187 (1974), pp. 63-89- o es un proceso psicológico o funcional -posición sostenida principalmente por Burnyeat, M.F., "Is an Aristotelian Philosophy of Mind Still Credible? (A Draft)", en: Nussbaum, M. y A.O. Rorty (eds.), Essays on Aristotle's De Anima. Oxford: Clarendon Press, 1992, pp. 15-26. Una recopilación detallada de la discusión entera y de las distintas posiciones, junto con una defensa de una posición intermedia se halla en Caston, V., "The Spirit and the Letter: Aristotle on Perception", en: Salles, R. (ed.) Metaphysics, Soul and Ethics: Themes from the Work of Richard Sorabji, Oxford: Oxford University Press, 2004, pp. 245-320. El pasaje parece apuntar a la versión funcionalista, sin embargo, es claro que no afirma que se "perciben las formas", sino que se "reciben". En todo caso, si hay o no hay cambio o modificación física en quien percibe, es claro el punto de Aristóteles según el cual la materia, en sí misma es incognoscible.

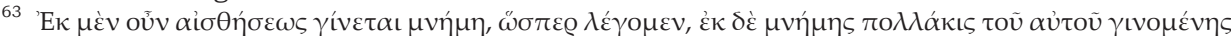

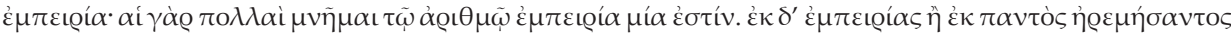

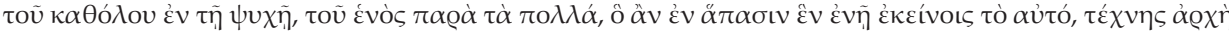

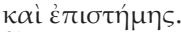

64 Barnes señala e intenta resolver un problema que aparece en Analíticos Posteriores II, 19. El problema consiste, básicamente, en que en este capitulo Aristóteles estaría dudando entre explicar la adquisición de "proposiciones primitivas" o la adquisición de "términos primitivos". El pasaje tendería a probar que se trata más de la adquisición de conceptos. Sin embargo, al
} 
esto con más detalle unas líneas más adelante: "Al quedar fijo un indiferenciado, [se fija] en el alma un universal primero (pues aunque se perciban particulares, la percepción es de lo universal, v.g., el hombre, pero no el hombre Calias), y a su vez se fija en estas cosas, hasta que se fije lo universal e inmediato, v.g., tal animal, hasta que [se fija] animal, y de igual manera con esto. Es evidente que para nosotros necesariamente se conocen los principios por inducción; pues, en efecto, de esta manera la percepción produce lo universal" (APo. 100a15-b5) ${ }^{65}$.

Aunque es claro que en los Analiticos Posteriores no hay una referencia explícita al hilemorfismo, y aun cuando el conocimiento de los primeros principios no conduzca ni a la forma ni a la esencia, como es el caso de la Metafísica, ambas posiciones son compatibles y es posible explicar una a partir de la otra ${ }^{66}$.

Hasta aquí, es preciso sacar dos conclusiones en lo que respecta al asunto de la "separabilidad" de la materia y de la forma. La primera de ellas es que, en una sustancia particular, son inseparables materia y forma; la segunda es, sin embargo, que en la medida en que dicha sustancia particular es percibida y conocida, se separa la materia de la forma, pues se percibe y se conoce exclusivamente la forma. El punto crucial de este excurso por el hilemorfismo aristotélico está en el hecho de que el intelecto, en tanto es el "lugar de las

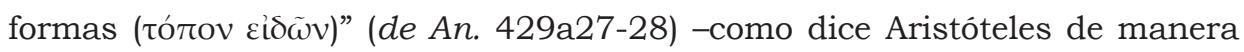
figurada, aludiendo seguramente a los platónicos- no es un "lugar", sino, más bien, el lugar de los conceptos; y, en este sentido, el concepto que hace posible, en general, tener conceptos y formas.

final Barnes intenta deshacer esta ambigüedad afirmando que, en términos de Aristóteles, si se adquieren los unos, también se adquieren los otros: "I feel obliged to concede that Aristotle did not realize that he was vacillating between two stories.... The conceptual sequence terminates in something which either is a propositional principle or at least immediately yields one. Secondly, Aristotle had a persistent tendency to treat definitions as the paradigm -or even as the sole- case of propositional principles" (Barnes, J., Aristotle's Posterior Analytics. Trans. with Commentary, Oxford: Clarendon Press, 1993, p. 271).

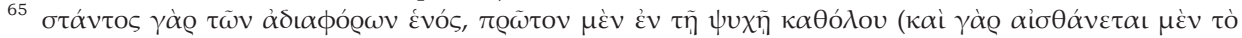

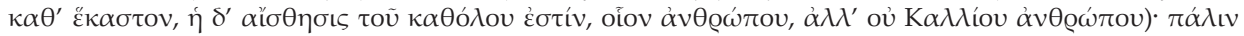

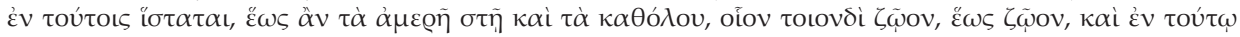

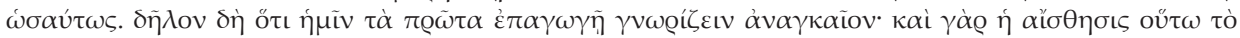

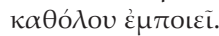

${ }^{66}$ Aun cuando haya referencias a la doctrina de las "cuatro causas" (APo. 94a21) y a la esencia (APo. 91a25, b8-10; 92a7-25; 93a12-19; 94a21-35), no aparece una conexión explícita entre la forma y la definición. Sin embargo, con respecto a la esencia, sí es clara su relación con la definición, y en particular con lo que Aristóteles dice sobre la definición en Metafisica VII, 4-6; 10-17. Sobre este punto, $c f$. Charles, D., Aristotle on Meaning and Essence, Oxford: Clarendon Press, 2000, cap. 11, y Charles, D., "Definition and Explanation in Aristotle's Posterior Analytics and Metaphysics", en: Charles, D. (ed.), Definition in Greek Philosophy, Oxford: Oxford University Press, 2010, pp. 286-328. 


\section{d. El intelecto "que viene desde afuera"}

Tal vez, la objeción más fuerte a la postura del Intelecto Divino es el hecho de que este venga "desde afuera ( $\theta \dot{\varrho} \alpha \theta \varepsilon v)$ " (GA, II, 3, 736b16-29). Es principalmente Alejandro de Afrodisia quien lo presenta de esta manera ${ }^{67}$. Sin embargo, la posición de Burnyeat no es exactamente esta, ni es, tampoco, la que intentamos defender aquí. La razón es, principalmente, la siguiente: hablar de un intelecto "que viene de afuera" es suponer que el intelecto es una pieza "física", como si se tratara, en el caso de los seres vivos, de la comida o algo de tales características que es posible de alguna manera "insuflar" en el ser vivo. Como si fuera posible construir al hombre de barro y luego "insuflarle" el intelecto.

Como señala Shields, el ejemplo de la luz en de An. III, 5 hace pensar que se trata efectivamente de un intelecto que viene de afuera. Sin embargo, como él mismo reconoce, es posible interpretar este ejemplo como si se tratara

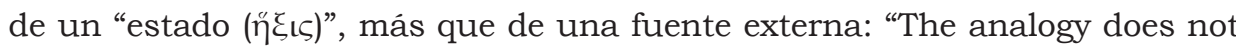
turn on the source but on the presence of light"68. Esta interpretación, atribuida por Shields a quienes defienden que se trata de un intelecto humano, señala un punto importante con respecto a que se trate de un intelecto "que viene de afuera", a saber, que es posible entender esta expresión de una manera simbólica y menos literal. Si tomamos la expresión este modo, estaríamos suponiendo que el intelecto es una sustancia material que "entra" en alguna parte. Esto es, sin embargo, atribuirle cualidades físicas que obviamente no posee, como la espacialidad o la materialidad.

Cuando Aristóteles menciona en GA que el intelecto es lo único que "viene de afuera" no puede hablar de manera literal sin contradecir toda su metafísica. Es contradictorio en particular con que el intelecto sea una "forma

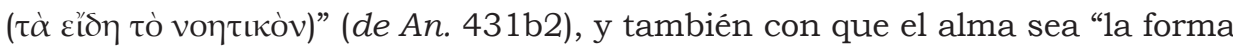

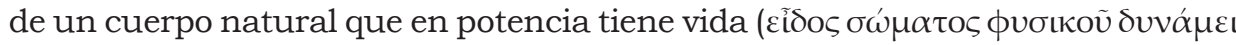

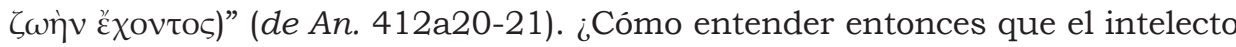
"viene de afuera"? Revisemos rápidamente el argumento de GA, que parece ser donde se defiende este asunto. Aristóteles afirma alli que "es preciso tener estas almas [nutritiva, sensitiva e intelectiva] antes en potencia que en acto. Y además, es preciso que, o sin que existan en un primer momento se formen

\footnotetext{
${ }^{67}$ Buena parte del argumento de Boeri contra Alejandro de Afrodisia se centra en este punto. Cf. Boeri, M.D., "Alejandro de Afrodisia como intérprete de la noética aristotélica", en: Estudios de Filosofia, XL (2009), pp. 91-92.

68 Shields, Ch., Aristotle. De Anima. Trad. \& Notes, p. 322. Énfasis en el original.
} 
todas dentro del ser, o que todas existan previamente, o que unas sí y otras no; y que se formen en la materia sin haber entrado en el esperma del macho o que estén ahí procediendo de este" (GA, 736b15-19) ${ }^{69}$.

Este problema que plantea aquí Aristóteles es importante con respecto del intelecto, pues parece ser la única facultad del alma que no puede existir solamente en potencia, a diferencia de lo que sucede con la sensación y la nutrición, las cuales, además, dependen de unas condiciones físicas para que se den: sin ojos es imposible la vista; aunque es posible tener la vista "en potencia" cuando se tienen los ojos cerrados. A diferencia de los sentidos, que están asociados a sus respectivos órganos, el intelecto no puede existir en potencia en lo absoluto, por no tener ningún órgano asociado. Así termina Aristóteles su argumento: "queda, entonces, que solamente el intelecto llegue desde fuera y que solamente él sea divino, pues en su actividad no participa para nada la actividad corporal" (GA, 736b27-29) ${ }^{70}$.

Lo que hace "divino ( $\theta \varepsilon \tilde{c} \mathrm{ov})$ " al intelecto y que "venga de fuera", es que en él no participa de la actividad corporal; pero no es porque "venga de fuera" que no tiene un órgano definido o que no requiera de unas condiciones físicas particulares para su desarrollo o su actividad, como sucede con los ojos y la visión ${ }^{71}$. Una vez más, cuando Aristóteles afirma que el intelecto agente "viene de fuera" lo hace, más bien, de manera metafórica y no literal. La razón por la que "viene de fuera" puede ser otra, a saber, que la actividad del intelecto agente es separable de la actividad física de la percepción; aun cuando esté ligada con esta e, incluso, como actividades sean indistinguibles (APo. 100a15-b5, supra §4.3). Así, la percepción viene de los órganos de los sentidos a través de su contacto con lo físico, pero la intelección "viene de fuera".

Interpretado de esta manera, el "intelecto que viene de afuera" tendría unas características completamente distintas a las que le han sido endilgadas a Dios como intelecto agente desde las intepretaciones de este como exclusivamente humano, como las de Filópono, Tomás e incluso Boeri. Así, ambas

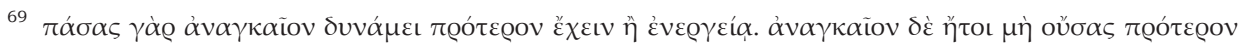

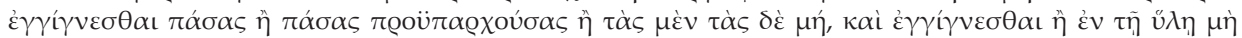

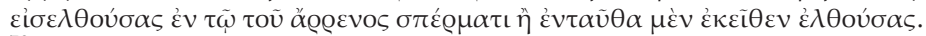

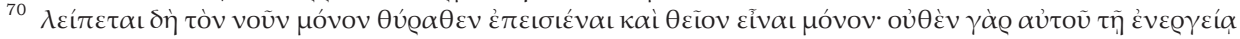

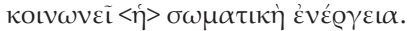

${ }^{71}$ Contrario a lo que opina, entre otros, Boeri, quien afirma que "si viene "desde afuera" es porque existe por sí independientemente de su anclaje en el cuerpo" (Boeri, M.D., "Alejandro de Afrodisia como intérprete de la noética aristotélica", en: Estudios de Filosofía, XL (2009), p. 104). Esta es justamente la interpretación que queremos controvertir, en particular ligada a la idea de Dios: que lo divino esté físicamente por fuera de todo lo material y, sobre todo, del ser humano.
} 
interpretaciones tendrían una cercanía considerable, pues el intelecto solamente sería activo en la medida en que, efectivamente, actúe o intelija. Esta parece ser, según Shields, la explicación de la interpretación del Intelecto Humano: "Aristotle is asserting that reason, insofar as it is active, is essentially in actuality"72. E1 intelecto parece, entonces, "venir de fuera" porque no es posible tener intelecto como potencia sin, a la vez, tenerlo en acto, no obstante, es imposible afirmar que el intelecto, físicamente, "entra" al ser humano ${ }^{73}$.

Si quitamos de la lectura del intelecto divino que este "entre" al ser humano, y aceptamos que el intelecto agente es especificamente humano, queda aún la pregunta respecto de cómo es posible que algo propiamente humano como el intelecto agente, sea, a su vez, divino. ¿Cómo es posible que una parte del ser humano tenga semejantes características? Esta es la pregunta que resolveremos en el final de nuestro escrito, pues, como queremos mostrar, siguiendo la interpretación de Burnyeat, lo "divino" es, a su vez, un aspecto del intelecto humano, pero, tal como hemos señalado con respecto a la distinción materia-forma, es solamente separado de manera conceptual. Así, lo divino es solamente captable por el intelecto humano y esto lo hace en virtud de que lo divino es, para Aristóteles, un concepto. No es, sin embargo, un concepto cualquiera, sino el concepto de concepto, y por lo tanto, la posibilidad de la existencia de cualquier otro concepto.

\section{e. La interpretación conceptual del Motor inmóvil}

Veamos, para culminar, la manera en que Burnyeat defiende su intepretación conceptual del motor inmóvil. Mostraremos algunas de las consecuencias que este autor presenta y mostraremos su plausibilidad. Respecto del intelecto inmortal, Burnyeat dice: "how does the immortal intellect help us? How does it make things intelligible to our mortal minds? Simply by existing, I would suggest, by being what it is: an eternal intellect constituted, like any other

72 Shields, Ch., Aristotle. De Anima. Trad. \& Notes, p. 324.

73 Algunos como Tomás de Aquino recurren, más bien, a la metáfora platónica de la "participación" para explicar este fenómeno: "And because this active force is a certain participation in the intellectual light of separated substances, the Philosopher compares it to a state and to light; which would not be an appropriate way of describing it if it were itself a separate substance" (In de An. 739). De esta manera Tomás resuelve el problema del carácter "divino" que Aristóteles le adjudica al intelecto agente: no porque sea divino en sentido estricto, sino porque "participa" de la divinidad. Sin embargo, asumir que el intelecto humano "participa" de la divinidad -un poco a la manera platónica, según la cual los particulares participan de la idea- no quiere decir que en sentido estricto el intelecto tenga la divinidad. Lo que hace Santo Tomás es entonces restarle importancia a la afirmación según la cual el intelecto es lo único que es eterno y divino. Pero, como afirmamos anteriormente, esto sería forzar en exceso el texto aristotélico. 
intellect, as a system of concepts. The difference is that the divine intellect is a system (better, perhaps, the system) of absolutely correct concepts. As such, the deity does not need to act on us from up high, but merely to illuminate the intelligible forms, somewhat in the way light, simply in virtue of being what it is, illuminates colours and makes them actually visible to us"74.

Con la idea de Burnyeat de que el intelecto inmortal es un sistema de conceptos, mas no cualquier sistema de conceptos, sino el sistema de conceptos, que queremos introducir que se trata, más bien del sistema normativo de conceptos: es el sistema según el cual se determina si todos los demás sistemas de conceptos - humanos e individuales- se encuentran acertados o equivocados. El hecho de que este intelecto, inmortal y divino, sea el sistema normativo de conceptos explica una de las características fundamentales del intelecto aristotélico, en general. Se trata, precisamente, de su infalibilidad. Así pues, cuando Aristóteles introduce el intelecto como "principio de principios" en Analíticos posteriores, afirma que "ningún otro género [de conocimiento] distinto de la intelección es más preciso que el conocimiento científico (oủঠèv

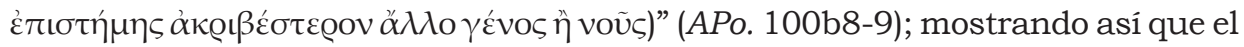

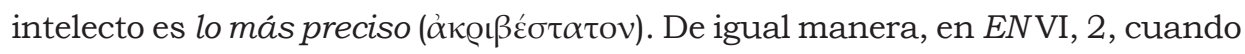
Aristóteles se refiere al principio de acción, afirma también que "la decisión

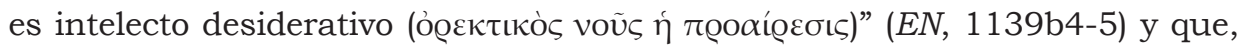
de este modo, la decisión es recta en la medida en que el deseo y el intelecto coinciden: lo que uno afirma, el otro persigue; así, en el caso de la acción y la elección, el intelecto también juega un papel normativo.

Para concluir, el hecho de que la vida de los dioses sea perfecta, tal como afirma Aristóteles al final de la Ética Nicomaquea y, por lo tanto, también la más feliz, no excluye la posibilidad de que la vida de los dioses no sea, al mismo tiempo, una vida humana. La vida de los dioses es la normatividad, de manera tal que, recomienda Aristóteles, "en la medida de lo posible [es preciso] volvernos inmortales, y hacer todo para vivir según lo más noble de lo que hay

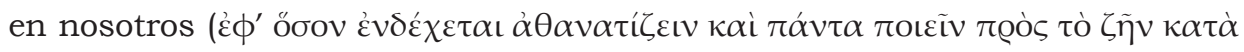

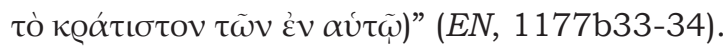

Así, tal como la forma no puede ser separada de la materia, a no ser conceptualmente, y así como el intelecto divino no se puede separar de lo físico sino conceptualmente, de la misma manera, la vida del intelecto no se puede separar de la vida propiamente humana sino conceptualmente; pues, como

${ }^{74}$ Burnyeat, M.F., Aristotle's Divine Intellect, pp. 40-41. 
termina afirmando Aristóteles, "lo propio para cada cosa según su naturaleza es lo más noble y placentero para cada uno; por lo que para el hombre será [lo más propio] la vida según el intelecto, dado que esto es principalmente el hombre. Por lo tanto, esta [vida] será la más feliz" (EN, 1178a5-8) ${ }^{75}$.

La conclusión de este pasaje es que la vida más propia del hombre es la vida de los dioses; es gracias al intelecto que el hombre puede alcanzar la felicidad. En efecto, la naturaleza del hombre es vivir de acuerdo al intelecto; es gracias al intelecto que el hombre puede vivir como un dios. Más aun, es con vistas a vivir como un dios que el ser humano realiza todas sus acciones: en la medida en que la naturaleza del hombre es vivir de acuerdo al intelecto, y en que la felicidad es la finalidad de todas las acciones humanas, la finalidad del hombre y, por lo tanto, su naturaleza, es vivir de acuerdo con el intelecto. Así lo expresa Aristóteles en la Política: "para nosotros [humanos], la razón y

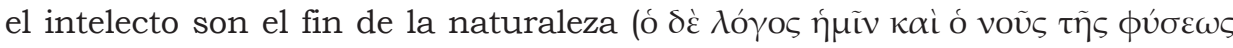

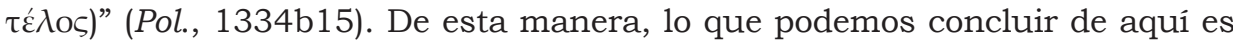
que, si el intelecto es divino, y es el principio normativo del ser humano, el fin del ser humano es, por lo tanto, llevar la vida de los dioses. Pero ello no implica que esta "vida de los dioses" no sea una vida humana; de hecho, esta "vida de los dioses" es la vida paradigmáticamente humana, en la medida en que lo intelectual y lo divino componen la esencia humana.

\section{Observaciones finales y conclusión}

Al identificar, de esta manera, el intelecto agente y la divinidad como normatividad, estamos mostrando que buena parte del debate entre las interpretaciones divina y humana del intelecto agente tenían como base una noción de divinidad posiblemente extraña a la que el mismo Aristóteles presenta. Probablemente sea un indicativo importante que quienes hayan defendido inicialmente la interpretación humana del intelecto agente hayan sido todos autores cristianos (Filópono, Sofonias, Tomás de Aquino) para quienes Dios es necesariamente una sustancia trascendente que no entra en composición con los demás seres (St. Tomás, Suma Teológica, I, q3, a8). Pero, en Aristóteles, la divinidad parece tener características distintas; pues no se trata de una sustancia más entre las demás sustancias físicas que hay en el mundo, pero con características metafísicas. Tampoco de una sustancia que exista en un universo

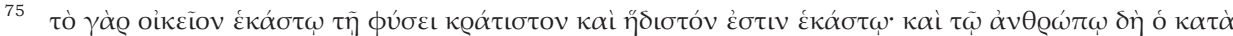

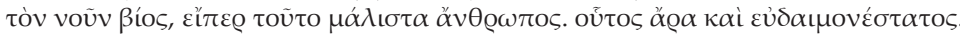


trascendente cuya sola existencia supondria un dualismo fuerte -quasiplatónico- que Aristóteles rechaza continuamente. Se trata, por el contrario, de un tipo de sustancia muy particular, que comparte, de cierta manera, su existencia con los demás seres y, en particular, con los seres humanos. La dificultad de comprender la divinidad en el pensamiento aristotélico es que esta se encuentra en el mismo mundo físico; es, solamente, un aspecto de este, pero no se encuentra "por fuera" del mundo físico. Lo que hemos presentado aquí, más allá de la larga discusión que hay sobre el concepto de "intelecto agente", es algunas líneas interpretativas sobre la noción de divinidad en Aristóteles, pero divinidad y humanidad no son dicotómicas y completamente separadas. Así, más allá de adjudicarle a la divinidad una existencia puramente subjetiva, otorgarle un valor conceptual y normativo hace posible que sea gracias a ella que los hombres tengan acceso a la objetividad y la imparcialidad. La divinidad se convierte, entonces, en un elemento de juicio y en el fundamento de todo criterio valorativo para el ser humano, tanto para el pensar como para la acción misma. De aquí que sea posible para el intelecto ser, además, práctico y tener injerencia en la acción: es la divinidad en el hombre lo que le permite encontrar lo acertado, lo correcto. Pero más aun, este intelecto divino no es exclusivo de cada hombre; por el contrario, es compartido por todos los hombres, es común a la especie en tanto todas comparten el mismo tipo de alma intelectiva. E1 intelecto es, entonces, no solo el lugar de las formas, sino, también, el lugar de los acuerdos entre los seres humanos.

Recibido: $21 / 03 / 2017$

Aceptado: 08/05/2018

\section{Bibliografia}

Alejandro de Afrodisia, "De Anima mantissa" [Mantissa], en: Praeter commentaria scripta minora: de Anima liber cum Mantissa, Bruns, I. (ed.), Commentiaria in Aristotelem Graeca. Supplementum Aristotelicum, vol. II.1, Berlin: Reimer, 1887, pp. 101-186. Aquino, T. de, A Commentary on Aristotle's De Anima, Pasnau, R. (trad.), New Haven \& Londres: Yale University Press, 1994.

Aquino, T. de, Suma Teológica, Madrid: Biblioteca de Autores Cristianos, 1989.

Aristóteles. "Analytica Posteriora", en: Analytica Priora et Posteriora, Ross, W. D. (ed.). Oxford: Oxonii, 1964, pp. 71-100.

Aristóteles, Aristotelis Physica, W. D. Ross (ed.), Oxford: Oxonii, 1966.

Aristóteles, Ethica Nicomachea, Bywater, I. (ed.), Oxford: Oxonii, 1894. 
Aristóteles, "Generatione Animalium", en: Aristotelis Opera, Bekker, I. (ed.), Berlin: Reimer, 1831, pp. 715-789.

Aristóteles, Metaphysica, Jaeger, W. (ed.), Oxford: Oxinii, 1957.

Aristóteles, Politica, Ross, W.D. (ed.), Oxford: Oxonii, 1957.

Barnes, J.. Aristotle's Posterior Analytics. Trans. with Commentary, $2^{\mathrm{a}}$ ed, Oxford: Clarendon Press, 1993.

Berti, E., "Aristotle's Nous Poietikos: Another Modest Proposal", 2nd International Colloquium on Aristotle, Interdisciplinary Centre for Aristotle Studies, 14 de mayo de 2014, disponible en: http://www.dikam.auth.gr/sites/default/files/attachements/Paper.pdf.

Boeri, M. D. (trad.), Aristóteles. Acerca del Alma - De Anima. Introducción, Traducción y Notas, Buenos Aires: Colihue, 2010.

Boeri, M. D., "Alejandro de Afrodisia como intérprete de la noética aristotélica", en: Estudios de Filosofia, XL (2009), pp. 79-107.

Bordt, M., "Why Aristotle's God is Not the Unmoved Mover", en: Oxford Studies in Ancient Philosophy, XL (2011), pp. 91-109.

Bostock, D., Aristotle Metaphysics Books $Z \& H$, Oxford: Oxford University Press, 1994.

Brentano, F., "Nous poiētikos: Survey of Earlier Interpretations" (1867), en: Nussbaum, M. C. y Rorty, A. O. (eds.), Essays on Aristotle's De Anima, Oxford: Oxford University Press, 1992, cap. 17, pp. 313-342. https://doi. org/10.1093/019823600X.003.0018

Burnyeat, M. F., "Is an Aristotelian Philosophy of Mind Still Credible? (A Draft)", en: Nussbaum, M. C. y Rorty, A. O. (eds.), Essays on Aristotle's De Anima, Oxford: Clarendon Press, 1992, cap. 2, pp. 15-26 https://doi. org/10.1093/019823600X.003.0003

Burnyeat, M. F., Aristotle's divine intellect, Winsconsin: Marquette University Press, 2008.

Bush, S., "Divine and Human Happiness in Nicomachean Ethics", en: Philosophical Review, CXVII, 1 (2008), pp. 49-75. https://doi.org/10.1215/00318108-2007-024

Caston, V., "Aristotle's Two Intellects: A Modest Proposal", en: Phronesis XLIV, 3 (1999): 199-227 https://doi.org/10.1163/15685289960500033

Caston, V., "The Spirit and the Letter: Aristotle on Perception", en: Salles, R. (ed.), Metaphysics, Soul and Ethics: Themes from the Work of Richard Sorabji, Oxford: Oxford University Press, 2004, cap. 11, pp. 245-320.

Charles, D., "Definition and Explanation in Aristotle's Posterior Analytics and Metaphysics", en: Charles, D. (ed.), Definition in Greek Philosophy, Oxford: Oxford University Press, 2010, pp. 286-328. https://doi.org/10.1093/acprof: oso/9780199564453.003.0009

Charles, D., Aristotle on Meaning and Essence, Oxford: Clarendon Press, 2000.

Charlton, W., Aristotle Physics Books I \& II, Oxford: Oxford University Press, 1970.

Davidson H. A., Alfarabi, Avicenna, and Averroes on Intellect, Oxford \& New York: Oxford University Press, 1992, pp. 13-18. 
Frede, M., "La théorie aristotélicienne de 1' intellect agent", en: Romeyer-Dherbey, G. y Viano, C. (eds.), Corps et âme. Sur le De anima d'Aristote, Paris: Vrin, 1996, pp. 377-390.

Gerson, L., “The Unity of Intellect in Aristotle's De Anima”, en: Phronesis XVIX, 4 (2004), pp. 348-373. https://doi.org/10.1163/1568528043067005

Hamlyn, D. W. (trad.), Aristotle - De Anima Books II and III, 2da ed., Oxford: Oxford University Press, 1993.

Hicks, R.D., Aristotle De Anima, with translation, introduction and notes, Cambridge: Cambridge University Press, 1907.

Johansen, T. K., The Powers of Aristotle's Soul, Oxford: Oxford University Press, 2012. https://doi.org/10.1093/acprof:oso/9780199658435.001.0001

Juan Filópono, In Aristotelis De Anima Libros Commentaria, Hayduck, M. (ed.), Commentaria in Aristotelem Graeca, vol. XV, Berlin: Reimer, 1897.

Judson, L., "Heavenly Motion and the Unmoved Mover", en: Gill, M. L. y Lennox, J. G. (eds.), Self-Motion: From Aristotle to Newton. Princeton: Princeton University Press, 1994, pp. 156-171

Kosman, L.A., “What does the Maker Mind Make?”, en: Nussbaum, M. C. y Rorty, A. O. (eds.), Essays on Aristotle's De Anima, Oxford: Oxford University Press, 1992, cap. 18, pp. 343-358 https://doi.org/10.1093/019823600X.003.0019

Lewis, F. A., "What's the Matter with Prime Matter?", en: Oxford Studies in Ancient Philosophy, XXXIV (2008): 123-146.

Makin, S. (trad.), Aristotle Metaphysics Book $\Theta$, Oxford: Clarendon Press, 2004.

Miller, F. D. Jr., "Aristotle on the Separability of Mind", en: Shields, Ch. (ed.), Oxford Handbook of Aristotle, Oxford: Oxford University Press, 2012, pp. 306-339. https://doi.org/10.1093/oxfordhb/9780195187489.013.0013

Plotino, Eneadas, 3 vols., Igal, J. (trad.), Madrid: Gredos, 1982-1998.

Polansky, R., Aristotle's De Anima, Cambridge, MA: Cambridge University Press, 2007. https://doi.org/10.1017/CBO9780511551017

Reeve, C. D. C., Action, Contemplation and Happiness, Cambridge, MA: Harvard University Press, 2012. https://doi.org/10.4159/harvard.9780674065475

Robinson H. M., "Aristotelian Dualism", en: Oxford Studies in Ancient Philosophy, I (1983), pp. 123-144.

Robinson, H.M., "Prime matter in Aristotle", en: Phronesis XIX, 2 (1974), pp. 168-188. https: / / doi.org/10.1163/156852874X00185

Rodier, G. (trad.), Traité de l'âme d'Aristote traduit et annoté, II vols. Paris: Leroux, 1900.

Ross. W. D., Aristotle. De Anima, Edited with Introduction and Commentary. Oxford: Oxford University Press, 1961

Scaltsas, T., “Aristotle's 'Second Man' Argument”, en: Phronesis, XXXVIII, 2 (1993), pp. 117-136. https://doi.org/10.1163/156852893321052352

Shields, Ch. Aristotle. De Anima. Trad. \& Notes. Oxford: Clarendon Press, 2016, pp. 315-316. 
Sisko, J., "Aristotle's Nous and the Modern Mind", en: Proceedings of the Boston Area Colloquium in Ancient Philosophy, XVI (2000), pp. 177-198. https://doi. org/10.1163/2213441700X00123

Sofonías, In Libros Aristotelis de Anima Paraphrasis, M. Hayduck (ed.,) Commentaria in Aristotelem Graeca, vol. XXIII, Berlin: Reimer, 1883.

Sorabji, R., "Body and Soul in Aristotle", en: Philosophy, XLIX, 187 (1974), pp. 63-89. https://doi.org/10.1017/S0031819100047884

Taylor, R. C., "The Agent Intellect as 'form for us' and Averroes's Critique of al-F'r'bî”, en: Proceedings of the Society for Medieval Logic and Metaphysics V (2005), pp. 18-32.

Temistio, In Aristotelis De Anima Paraphrasis. Heinze, R. (ed.), Commentaria in Aristotelem Graeca, vol. V.3, Berlin: Reimer, 1899.

Wedin, M., "The Science and Axioms of Being”, en: Anagnostopoulos, E. (ed.), A Companion to Aristotle, Londres: Wiley-Blackwell, 2009, cap. 8, pp. 137-141. 